\title{
Task 4 - Natural Gas Storage - End User Interaction
}

\author{
Topical Report \\ February 18, 1997
}

\section{RECEIVED \\ AllG 121997 \\ OS TI}

Work Performed Under Contract No.: DE-AC21-94MC31114

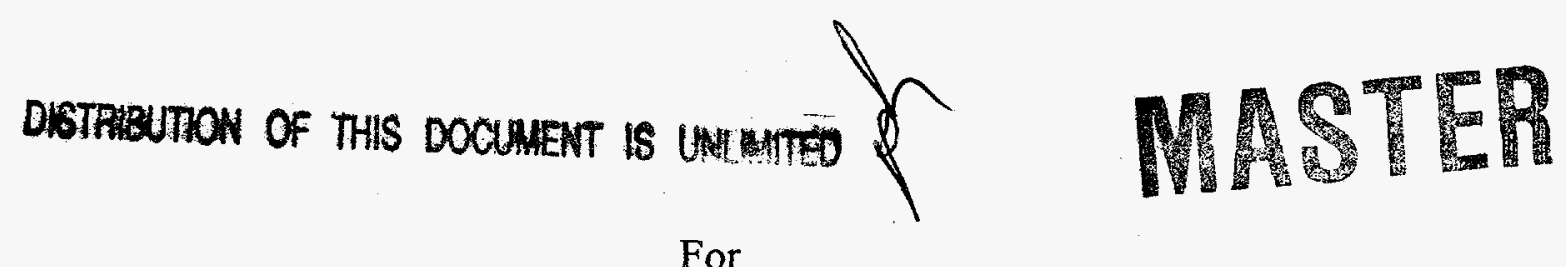

U.S. Department of Energy Office of Fossil Energy

Federal Energy Technology Center

Morgantown Site

P.O. Box 880

Morgantown, West Virginia 26507-0880

By.

ICF Resources, Inc.

9300 Lee Highway

Fairfax, Virginia 22031-1207 


\section{DISCLAIMER}

Portions of this document may be illegible electronic image products. Images are produced from the best available original document. 


\section{Disclaimer}

This report was prepared as an account of work sponsored by an agency of the United States Government. Neither the United States Government nor any agency thereof, nor any of their employees, makes any warranty, express or implied, or assumes any legal liability or responsibility for the accuracy, completeness, or usefulness of any information, apparatus, product, or process disclosed, or represents that its use would not infringe privately owned rights. Reference herein to any specific commercial product, process, or service by trade name, trademark, manufacturer, or otherwise does not necessarily constitute or imply its endorsement, recommendation, or favoring by the United States Government or any agency thereof. The views and opinions of authors expressed herein do not necessarily state or reflect those of the United States Government or any agency thereof. 


\section{TABLE OF CONTENTS}

Executive Summary

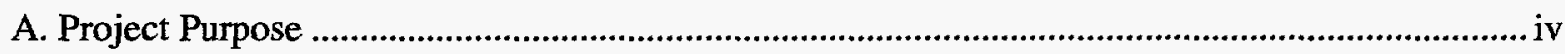

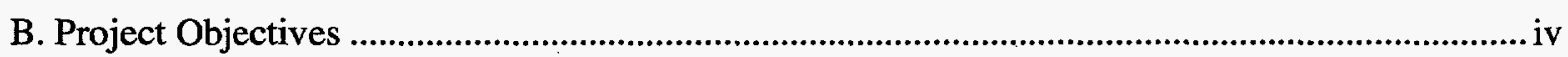

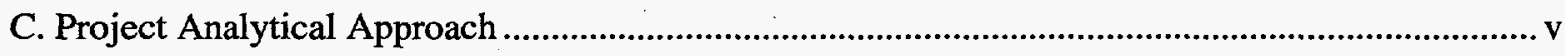

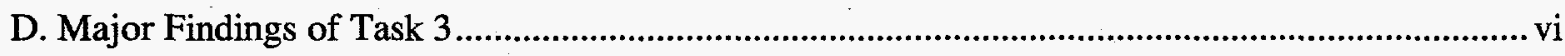

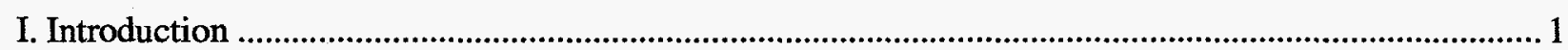

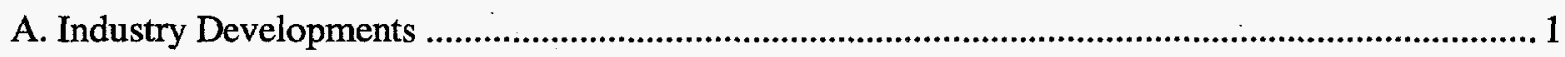

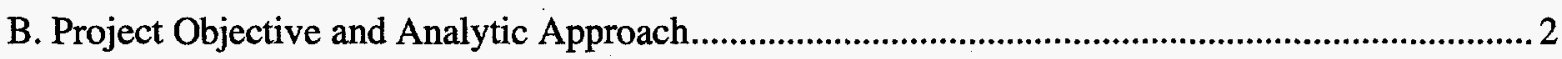

C. The Uses of Underground Gas Storage and Its Operational Aspects .......................................... 2

1. Balancing Supply with Demand ............................................................................................. 2

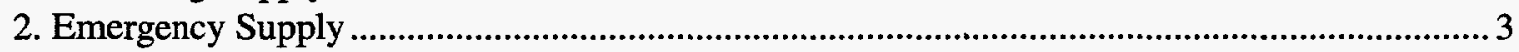

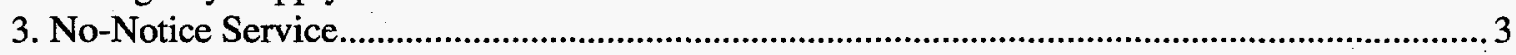

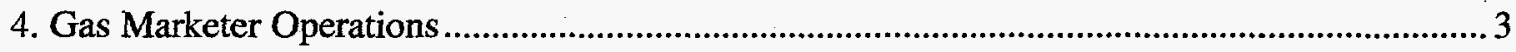

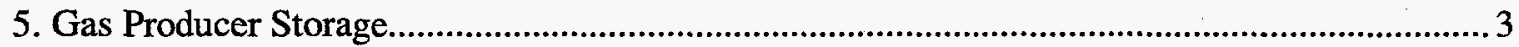

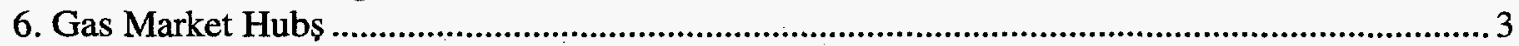

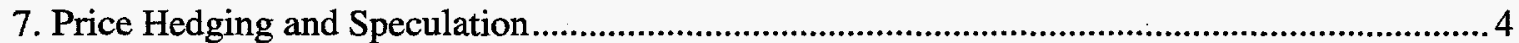

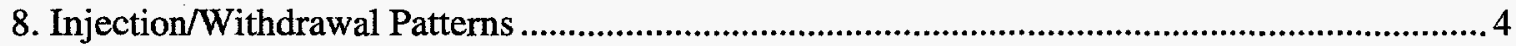

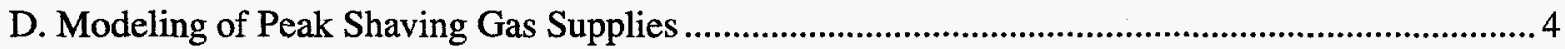

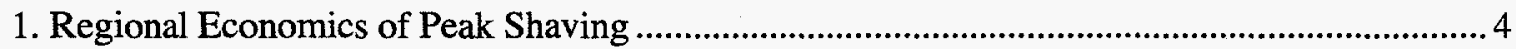

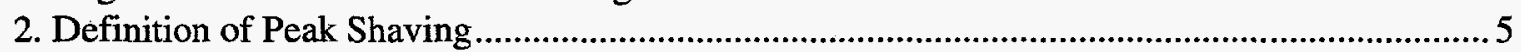

3. Justification of Peak Shaving Investments ..........................................................................5

4. Model Assumptions for Peak Shaving Supplies.....................................................................5

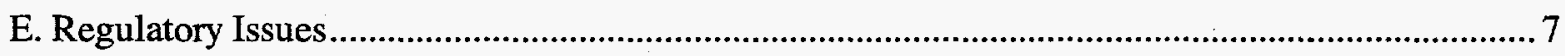

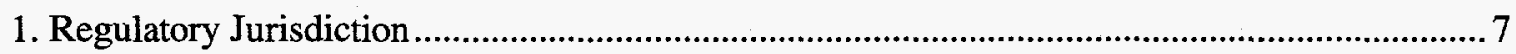

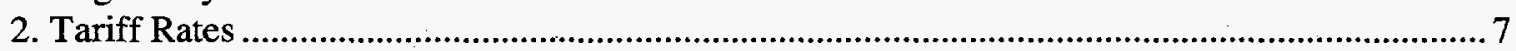

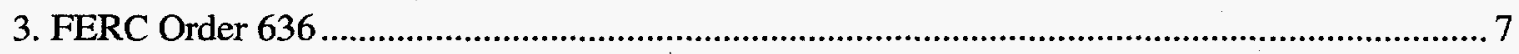

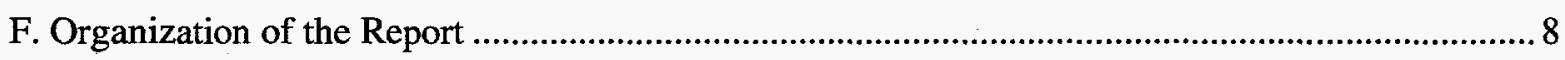

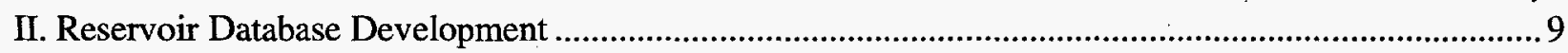

A. Database For Existing Gas Storage Reservoirs..............................................................................

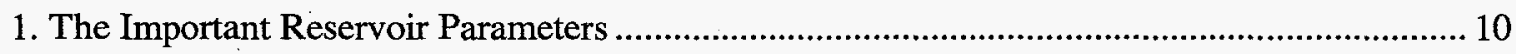

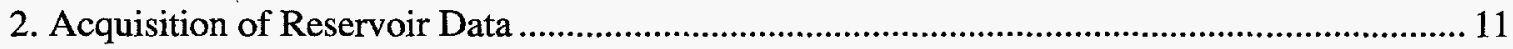

B. Database For New/Potential Storage Reservoirs ................................................................. 13

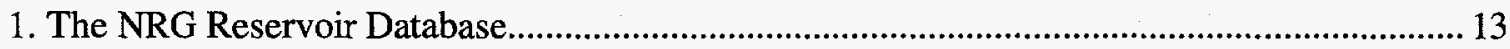

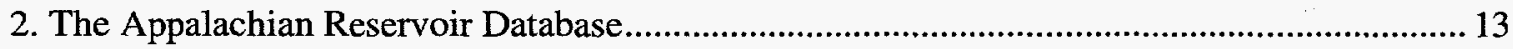




\section{TABLE OF CONTENTS (CONTINUED)}

$\underline{\text { Page }}$

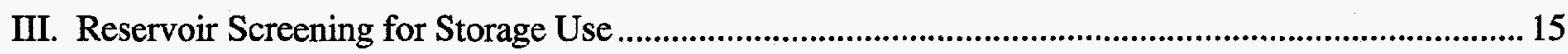

A. Technical Screening Criteria for Storage .......................................................................... 15

B. Estimation of Missing Storage Reservoir Properties ........................................................... 16

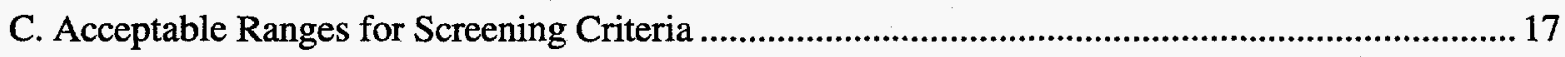

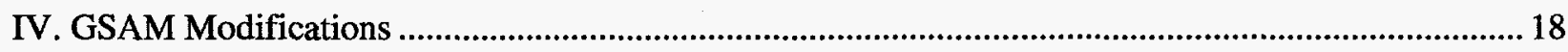

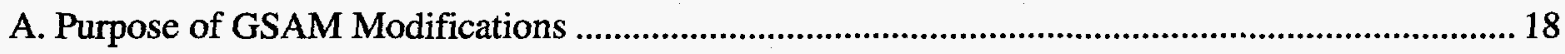

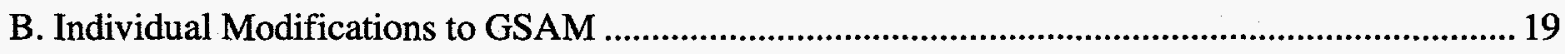

C. Modeling Methodology of Storage Reservoir Performance Module (SRPM)............................ 19

D. Modification of GSAM's Operating Routines to Allow Gas Withdrawa1/Injection .................... 20

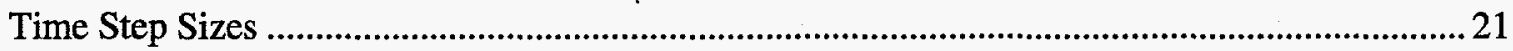

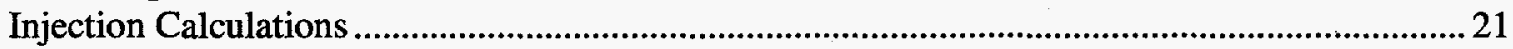

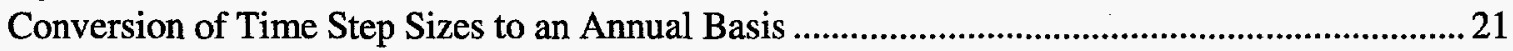

E. Modification of the Reservoir Performance Module of GSAM................................................... 21

F. New Technology Performance and Cost Relationships ......................................................... 22

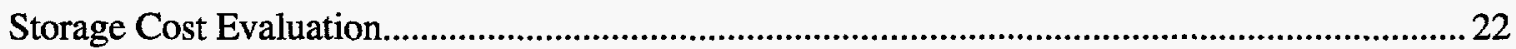

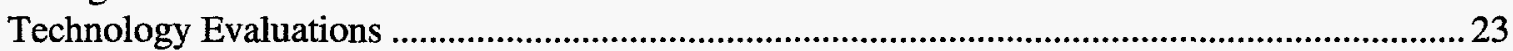

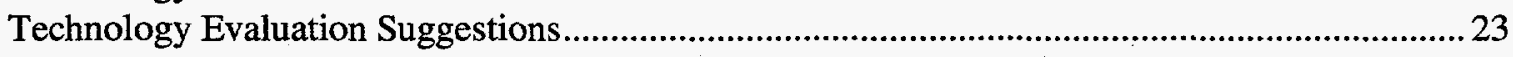

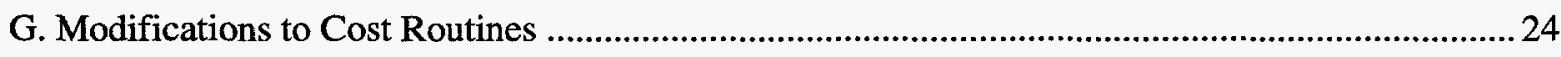

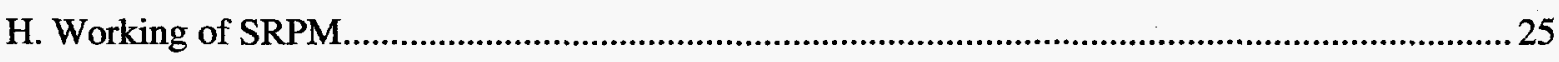

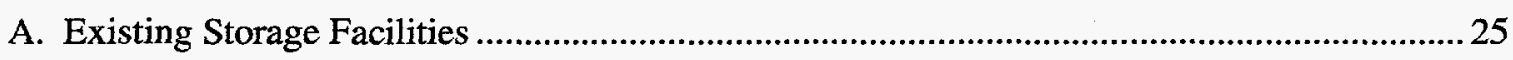

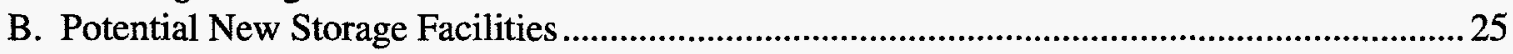

I. Modification of the Demand and Integrating Module ......................................................... 28

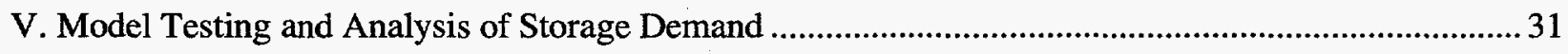

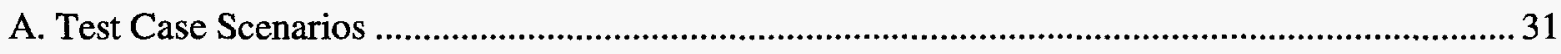

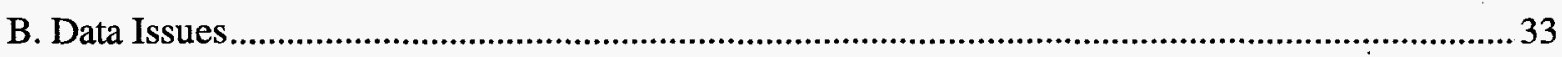

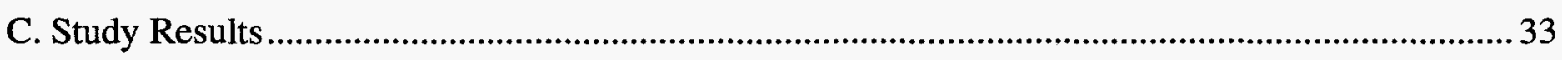

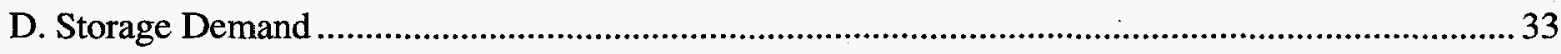

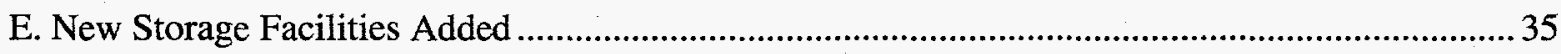

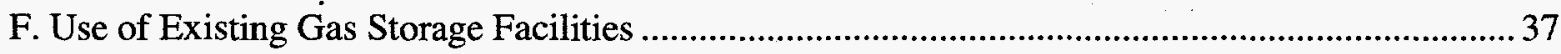

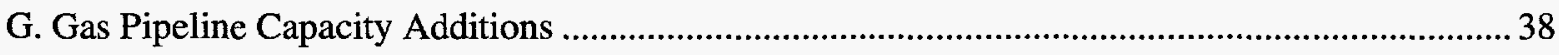

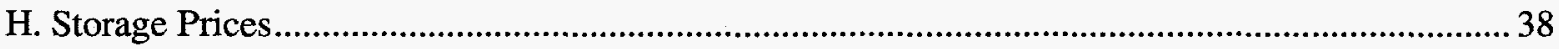

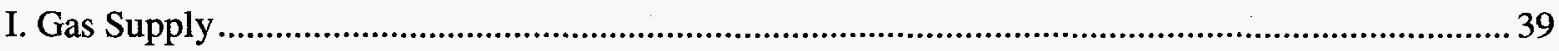

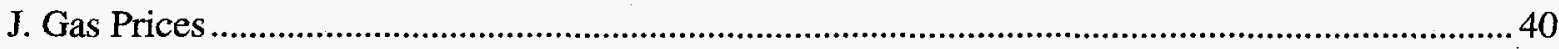




\section{TABLE OF CONTENTS (CONTINUED)}

LIST OF FIGURES $\quad$ Page

FIGURE II-1 Development Procedure for the Reservoir Database................................................... 12

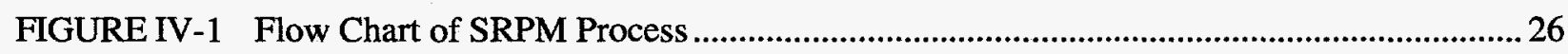

FIGURE IV-2 Illustration Of SRPM Process In Calculating Deliverability......................................... 27

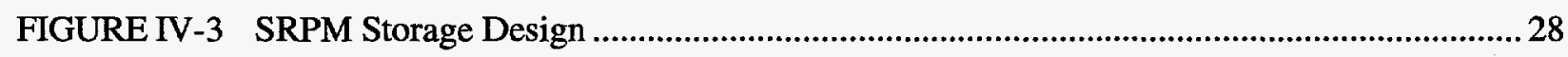

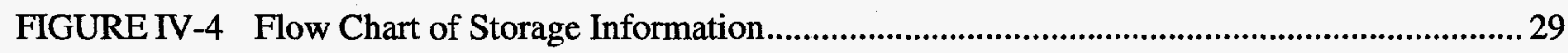

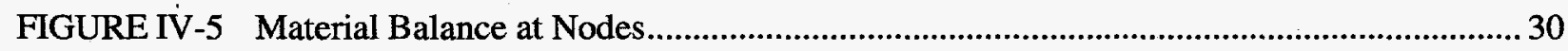

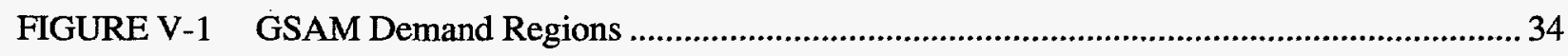

\section{LIST OF TABLES}

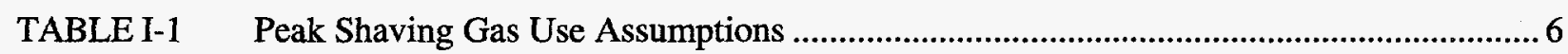

TABLE I-2 Peak Shaving Gas Cost Assumptions .......................................................................

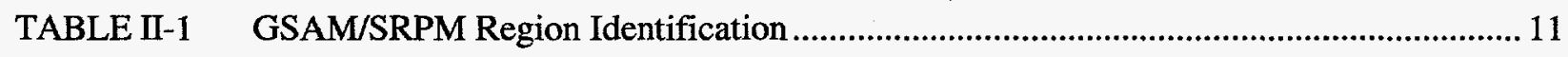

TABLE III-1 Minimum Reservoir Volume by Depth Criteria ......................................................... 16

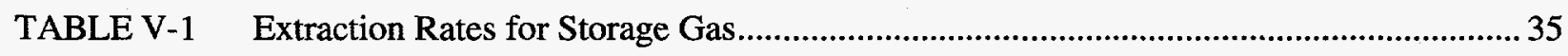

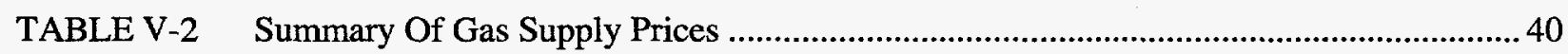

TABLE V-3 Examples of Regional Gas Prices for Electric and Residential Sectors.......................... 41 


\section{EXECUTIVE SUMMARY}

New opportunities have been created for underground gas storage as a result of recent regulatory developments in the energy industry. The Federal Energy Regulatory Commission (FERC) Order 636 directly changed the economics of gas storage nationwide. Pipelines have been required to "unbundle" their various services so that pipeline users can select only what they need from among the transportation, storage, balancing and the other traditional pipeline services. At the same time, the shift from Modified Fixed Variable (MFV) rate design to Straight Fixed Variable (SFV) rate design has increased the costs of pipeline capacity relative to underground storage and other supply options. Finally, the ability of parties that have contracted for pipeline and storage services to resell their surplus capacities created by Order 636 gives potential gas users more flexibility in assembling combinations of gas delivery services to create reliable gas deliverability. In response to Order 636, the last two years have seen an explosion in proposals for gas storage projects.

Another major development affecting the demand for storage is the restructuring of the electric power industry. The trend began with the passage of the Public Utilities Regulatory Policies Act (PURPA), which allowed non-utility electric generators, or qualifying facilities, to provide electric power to electric utilities. Since 1978, substantial amounts of cogeneration and independent power capacity have come on line. Repeal of the Fuel Use Act enabled this capacity to be built with efficient gas-fired turbine technologies. The Energy Policy Act of 1992 and newly proposed FERC regulations will further facilitate the break-up of the electric power industry into independent generators, transmission companies, and distribution utilities. The fuel of choice for most cogeneration and independent power has been, and probably will continue to be, natural gas. Since many of these units are not the lowest cost generation sources available to a utility, they may not be operated full time. Thus, they use gas intermittently over time, which may increase the need for storage.

\section{A. Project Purpose}

The primary purpose of this project is to develop an understanding of the market for natural gas storage that will provide for rigorous evaluation of federal R\&D opportunities in gas storage technologies, operating practices, and approaches for information management.

\section{B. Project Objectives}

The primary objectives of the project are:

1. To identify market areas and end-use sectors where new. natural gas underground storage capacity can be economically employed;

2. To develop a storage evaluation system that will provide an analytical tool to evaluate storage requirements under alternative future economic, technology, and market conditions; and

3. To analyze the economic and technical feasibility of alternatives to conventional underground gas storage. 


\section{Project Analytical Approach}

To meet the aforementioned objectives, an analytical approach was developed to simulate the decision making process used by storage developers in deciding where, how much, when, and what type of storage facility would be economic. Initially, it was thought that these decisions could be made based on the concept that gas demands of various types of end-users within a given region could be satisfied by storage capacities within that region. As described below, this initial approach had to be modified to examine storage needs and economics on a total North American gas system basis, and to recognize that in today's gas market, storage is of interest to many more parties than just the end-users.

Both the initial and final approaches to determining the need for storage in a region recognize that there are two primary conditions that must exist to make storage economic. The first condition is that there must be seasonal or shorter-term changes in gas demands of end-users each year. If all consumers used constant amounts of gas all year long, there would be no economic justification for storage. This occurs because pipeline transportation rates are less expensive than storage rates, if the pipeline capacity is near fully utilized. Secondly, there must be differences in the cost of gas and/or the cost of gas delivery during the year. If the price of gas and its transportation costs did not vary over the course of a year, storage would simply be an additional cost to add to the total cost of delivered gas.

This project has been divided into six tasks. Tasks 1,3 , and 5 are the analytical assignments that respond to the three primary objectives listed above. Tasks 2,4 , and 6 are the written reports for the three analytical tasks. Task 1 defines the storage market, including identification of existing and proposed storage facilities and their costs, development of an analytical basis for comparing the economics of gas storage with its competitors, and preliminary identification of where additional storage may be required. Task 3 involves development of a data base and screening criteria for existing and potential storage reservoirs, and modification of DOE's Gas Systems Analysis Model (GSAM) to evaluate the effects of technology changes on storage reservoirs in much the same way as on production reservoirs. Task 5 involves the evaluation of a range of alternative storage technologies under varying market conditions.

The primary work items involved in completion of Task 3 of this gas storage analysis project are:

- development of the storage reservoir technical and economic screening criteria for identifying reservoirs that have potential for gas storage;

- modification of the GSAM upstream models as required to predict reservoir performance under conditions of gas injection and withdrawal cycles;

- testing the modified GSAM performance in identifying reservoirs with storage potential against known storage reservoirs; and

- characterization of regional storage potential through identification of target storage reservoirs.

These work items have been completed and a brief summary of the Task 3 findings is provided in the following section. 


\section{Major Findings of Task 3}

The gas storage module for GSAM was tested in four supply/demand and technology scenarios that provided insights on how economic and technological changes will affect the demand for gas storage capacity. In other words, an attempt was made to examine potential future requirements for gas storage that account for several possible futures in the North American gas market. A Base Case, that represents essentially the status quo, is used as a benchmark against which the other three cases are compared. The Low Demand and High Demand Cases differ from the Base Case in the amount of gas demand growth they experience for fueling electric power generation. In the Low Demand Case, coal wins the competition with gas for this growth sector. In the High Demand Case, gas wins the competition for power generation fuel. In the Technology Case aggressive advancements are assumed in technology for both exploration and production and for storage reservoirs. The major findings from testing these four scenarios are listed below.

1. Among the four scenarios tested, the greatest use of storage as measured by annual gas extraction rates occurs in the Technology Case, wherein total U.S. gas extraction declines from $1,185 \mathrm{Bcf}$ in the year 2000 to $854 \mathrm{Bcf}$ in 2010 . The Base Case uses the least amount of storage at from 1,077 to $765 \mathrm{Bcf}$ between the years 2000 and 2010 . The following table summarizes the total U.S. forecast gas extraction rates for each of the four cases. In all cases, the use of storage declines by 26 to 29 percent between 2000 and 2010 . This decline in storage utilization occurs because most of the growth in gas demand is for power generation rather than for the temperature-sensitive residential and commercial loads that improve the economics for gas storage.

\section{Extraction Rates for Storage Gas, Bcf}

\begin{tabular}{|c|c|c|c|}
\hline & 2000 & $\underline{2005}$ & $\underline{2010}$ \\
\hline Base Case & 1,077 & 905 & 765 \\
\hline Low Demand Case & 1,144 & 1,013 & 843 \\
\hline High Demand Case & 1,098 & 931 & 776 \\
\hline Technology Case & 1,185 & 1,050 & 854 \\
\hline
\end{tabular}

2. The number of new gas storage reservoirs developed varies from four in the Base Case to 11 in the Technology Case. Only four demand regions are projected to add new storage capacity in any of the cases analyzed, the East North Central, West South Central, Mountain South, and California. In the Low Demand Case, eight new storage facilities are forecast as required in the U.S., while in the High Demand Case, the projection is for development of six new storage facilities.

3. In addition to selecting reservoirs for development as new storage facilities, the integration module also selects which of the existing storage facilities are economic to use. Annual utilization of existing storage capacity varied widely among the regions and the scenarios tested. The higher utilization rates are in the Middle Atlantic, South Atlantic, East South Central and California regions. These rates varied from 90 to 100 percent utilization. The lower utilization rates appeared in the East North Central, West North Central, and Pacific Northwest regions. The utilization rates among these latter four regions varied from zero to 60 percent. These results indicate that in the Middle Atlantic, South Atlantic, East South Central, and California regions the reservoir deliverability received per unit of service cost is better with most of the existing storage facilities that it would be with new facilities. On the other hand, these results indicate that the East North Central, West North Central, and Pacific 
Northwest regions, probably have more storage capacity than the market demands. In the case of the East North Central region and California, these results indicate that some existing storage facilities are not as economic as new facilities, because these two regions are among the four regions where new facilities are forecast to be developed.

4. The existing storage facilities selected for use by the storage module also change with the scenario analyzed. For example, in the Base Case, 13 of the 23 existing storage facilities in the Mountain North region are selected for use. In the Low Demand Case, one additional storage facility is selected for use, bringing the total to 14 active storage facilities in the Mountain North region. Considering all regions, the Low Demand Case has 10 existing storage reservoirs scattered among four regions added to the Base Case total. In the High Demand and Technology Cases, several existing storage facilities were added to the Base Case roster and several were deleted. In the High Demand Case, the larger decline in storage demand resulted in deletion of three storage reservoirs that were used in the Base Case. In the Technology Case, the single reservoir deletion from the list of existing storage reservoirs used in the Base Case indicates that the more aggressive technology advancements assumed for this scenario has improved the economics of using some reservoirs relative to others. In other words, some of the idle reservoirs of the Base Case are more susceptible to technology improvements than those used in the Base Case.

5. The High Demand Case requires less gas storage capacity because essentially all of the gas demand increase over the Base Case occurs in the power generation sector. This added load takes the place of storage because gas use for generation is typically a summer load that reduces the seasonality of demand, making better year-round use of pipeline capacity. The Low Demand Case has less electric generation demand and has greater seasonal swings in gas demand, improving the economics for storage.

6. Substantial pipeline capacity is added to transport gas from the Gulf - of Mexico West to Texas Gulf Coast and from the Mid-Continent to Mountain North regions in all four scenarios. Other significant pipeline capacity additions are projected from the San Juan to Mountain North and from the Permian to San Juan. The regions receiving gas through these expansions are not included in regions projected to need gas storage because in these instances pipeline capacity was determined to be more economic than storage.

7. Prices for the gas storage service used in the four scenarios vary widely within each storage region and among the four scenarios tested. Prices, based on company tariff rates for existing facilities and reservoir development cost estimates for new storage facilities, vary from as little as $\$ 0.17$ to $\$ 1.63$ per Mcf stored. The lower prices are typically for older facilities that had lower investments for facility development and for the base gas.

8. Because GSAM is structured to recognize only two seasons and the winter season is 151 days long, the economic advantage of gas storage is understated in this study. Since there is no recognition of the higher winter loads that typically occur for shorter periods, the full advantage of both peak shaving and shorter-cycle storage cannot be determined. As structured now, gas pipeline capacity is justified over 151 days of constant demand. This constant demand can be an average of 151 days that have peak gas demands several times the average demand. Since pipeline capacity rarely can be justified for the gas demands of the coldest ten to 30 days of winter, this average winter load is unrealistic.

9. Despite the understatement of the demand for gas storage, this study does support anecdotal information from the trade press and from contacts with storage operators that storage capacity is overbuilt in several regions. Regions where additional storage capacity will be required are identified. The differences in the need for storage have been developed, 
depending on whether or not gas wins in the competition with coal for the power generation market and on the level of technology advancement assumed.

10. The storage module of GSAM has been prepared to incorporate aquifer and salt cavern storage facilities whenever data bases for these formations are developed.

These findings, along with the storage capacity and cost data bases developed for both the existing and planned storage facilities, directly support planned efforts for the Task 5 effort under way now. 


\section{INTRODUCTION}

The Task 2 report for this project, completed in January 1996, focused primarily on describing the types, capacities, and costs of natural gas storage facilities that are available and the markets that gas storage is required to serve. This Task 4 report describes the modifications that have been made to the Gas Systems Analysis Model (GSAM) for evaluating prospective storage projects under varying technical, economic, and regulatory conditions. Initial tests of the modified model have selected a stratified list of potential future storage reservoirs and their costs of service. The Task 6 report, due later in 1997, will provide the results of more extensive model tests under varying scenarios.

\section{A. Industry Developments}

New opportunities have been created for underground gas storage as a result of recent regulatory developments in the energy industry. The Federal Energy Regulatory Commission (FERC) Order 636 directly changed the economics of gas storage nationwide. Pipelines have been required to "unbundle" their various services so that pipeline users can select only what they need.from among the transportation, storage, balancing and the other traditional pipeline services. At the same time, the shift from Modified Fixed Variable (MFV) rate design to Straight Fixed Variable (SFV) rate design has increased the costs of pipeline capacity relative to underground storage and peak shaving ${ }^{1}$ options. $^{2}$ Finally, the secondary market ${ }^{2}$ in pipeline and storage services created by Order 636 gives potential gas users more flexibility in assembling combinations of gas delivery services to create reliable gas deliverability. In response to Order 636, the last two years have seen an explosion in proposals for gas storage projects.

Another major development affecting the demand for storage is the restructuring of the electric power industry. This trend began with the passage of the Public Utilities Regulatory Policies Act (PURPA), which allowed non-utility electric generators, or qualifying facilities, to provide electric power to electric utilities. Since 1978, substantial amounts of cogeneration and independent power capacity have come on line. Repeal of the Fuel Use Act enabled this capacity to be built with efficient gas-fired turbine technologies. The Energy Policy Act of 1992 and newly proposed FERC regulations will further facilitate the break-up of the electric power industry into independent generators, transmission, companies, and distribution utilities. The fuel of choice for most cogeneration and independent power has been, and probably will continue to be, natural gas. Since many of these units are not the lowest cost generation sources available to a utility, they may not be operated full time. Thus, they use gas only intermittently over time.

\footnotetext{
${ }^{1}$ The two primary peak shaving options are liquefied natural gas (LNG) and propane and air mixtures. LNG supplies can be from imports and by liquefaction of pipeline gas during warmer months. Peak shaving operations are typically performed by local gas distribution companies (LDCs).

${ }^{2}$ Secondary markets for pipeline and storage services were created when Order 636 allowed the parties that have contracted for those services to resell their surplus capacity.
} 


\section{B. Project Objective and Analytic Approach}

The primary objectives of this project are: 1) to identify U.S. market areas and end-use sectors where new natural gas underground storage capacity can be economically employed, 2) to provide the Morgantown Energy Technology Center (FETC) with a storage evaluation system that will provide the analytical tools necessary for it to evaluate storage requirements under alternate future economic, technology, and market conditions, and 3) to analyze the feasibility of alternatives to conventional gas storage methods.

In order to meet these objectives, an analytic approach was developed to determine the critical decision parameters used by new storage field developers in deciding to develop a new storage project. These decisions focused on two areas:

- Technical Issues: What is the technical capability of the site including, working gas capacity, deliverability and injection rates, investment and operating costs, and location?

- Market Issues: Is there a market for the storage, considering the alternatives available in energy markets, including potential advancements in underground storage technology?

\section{The Uses of Underground Gas Storage and Its Operational Aspects}

In general, the operation of an underground gas storage facility typically involves: 1) injecting the desired volume of pipeline gas into the reservoir using pipeline pressure and onsite compressors to augment the pipeline pressure, if necessary, as reservoir pressure builds up during injection, 2) monitoring storage pressure during static periods to determine leakage rates, 3) withdrawing gas from the reservoir when it is needed, using reservoir pressure initially, 4) processing the stored gas to remove water, liquid hydrocarbons, and any other impurities, and 5) compressing the stored gas to pipeline pressure whenever the reservoir pressure is inadequate.

In the past, when most gas storage was used to supplement pipeline gas supply during the winter season when gas demand was highest, the operations described above were essentially a seasonal (one cycle per year) task. Gas was withdrawn during cold weather and reinjected during the warmer months - with some injection during winter months, if temperatures moderated. With the restructuring of the gas industry under FERC Order 636 and rapid increases in high deliverability, salt cavern storage, new forces are at work shaping the way storage is used. The pipelines no longer control how most of the storage capacity is used. The downstream gas shippers, LDCs, and large consumers that have contracted for the storage make the decisions on when and how much to inject and withdraw. The pipelines have retained just enough storage capacity to manage their own operations. Pipeline company use of storage now is very like a surge drum to handle short-term differences in the amount of gas being placed into and taken from the line.

Although most shippers still use much of their storage capacity in the traditional way, to augment pipeline capacity in times of heavy seasonal demands, the following newer uses have gained importance in recent years.

\section{Balancing Supply with Demand}

Because a typical gas shipper cannot accurately estimate the amount of gas it will need every day, there will be daily imbalances between the gas the shipper places into the pipeline and takes from the pipeline. Some will take more gas than they placed into the pipeline and others will leave gas in the 
line. The pipeline can usually manage the net daily imbalance with its load management storage. If individual shippers have a substantial daily imbalance they can be charged a penalty amount for causing pipeline load management problems. More typically, the daily imbalances are acceptable and a monthly imbalance penalty is of more concern. Because monthly imbalance penalties charged by pipelines can be sizable, shippers frequently use storage to balance their gas supplies and demands.

\section{Emergency Supply}

In the past, when the gas pipelines were fully responsible for serving the contracted demands of their customers, problems with gas supply at the producer level were typically solved by the pipeline. The pipeline customers might have peak shaving supplies that would serve as emergency supplies for a few hours or days. When a pipeline had a supply problem, it used gas from its storage or obtained gas from other suppliers and/or pipelines. As common carriers, pipelines no longer have this supply responsibility, except for small portions of their throughput that is sold to very small consumers that cannot find and purchase their own gas and contract for transportation. Thus, shippers now need to have their own methods of handling supply emergencies. For supply problems that affect major percentages of their total supply or last for several days, gas storage is an obvious solution for shippers.

\section{No-Notice-Service}

A relatively new service offered by gas pipelines that can provide shippers a substitute for having their own storage is no-notice service. If a shipper (that has contracted with a pipeline for no-notice service) experiences gas demand in excess of the pipeline transportation volume nominated for a day, the shipper can call on its pipeline to transport the deficit up to the maximum daily quantity of the no-notice contract. The pipeline has no obligation to provide the gas transported under no-notice service, however. The storage that the pipeline may need to supply this no-notice service can be a part of the operational storage capacity that FERC Order 636 allows interstate gas pipelines to retain.

\section{Gas Marketer Operations}

The unbundling of gas service by interstate gas pipelines, as required by FERC Order 636, combined with the desire of many past pipeline customers to retain a bundled supply and delivery service, has prompted gas marketers to offer this comprehensive service. To help balance their supply and delivery volumes and meet emergencies, many of the marketers have contracted for or purchased storage capacity.

\section{Gas Producer Storage}

Gas producers are using field area storage to help maintain a constant flow of gas from their wells and to back up their production commitments in case of field equipment problems. Both conventional depleted reservoir and salt cavern storage are used for these purposes.

\section{Gas Market Hubs}

FERC Order 636 encourages the development of market centers or hubs at locations where several interconnected gas pipelines can facilitate physical gas trades among multiple sellers and buyers. The need for storage to balance these physical trades on a day-to-day basis has led to many hubs being located where storage is available or is being developed. 


\section{Price Hedging and Speculation}

Because of the fairly regular seasonal cycles in gas prices and the more general price volatility that exists since gas prices were decontrolled, there are opportunities for those who have storage capacity to buy gas when prices are at the lower end of the seasonal swings. LDCs and marketers that have storage capacity try to take advantage of these opportunities to minimize their gas costs. The challenge in this practice is to find a combination of a lower gas price plus a storage cost that is lower than the higher price of gas in the season of higher demand. These hedging operations use conventional gas storage. Operators and users of high deliverability storage, which is several times as costly as conventional storage, can speculate on the rise and fall of gas prices - cycling their capacity several times each year in some cases. The ability to cycle several times per year can offset the additional costs of high deliverability storage, if the speculator anticipates price swings accurately most of the time.

\section{Injection/Withdrawal Patterns}

An informative measure of average operations for gas storage facilities is their pattern of gas injections and withdrawals over a period of time. The DOE/EIA publishes monthly data on gas storage injections and withdrawals by states which show general patterns of gas flows in and out of storage.

In late 1993, the American Gas Association (AGA) began publishing weekly reports of estimates of the working gas storage, regionally and nationally. These reports for the first time give weekly data on net storage injection and withdrawal volumes. Since the AGA data do not show separate volumes for injections and withdrawals, the total in and out movements are missed. This omission is most critical in locations such as California, where high deliverability reservoirs and the lack of a severe winter season allow substantial short-term cycling of storage all year.

AGA collects the statistical information on underground storage from more than 35 companies which account for about 85 percent of total working gas capacity in the U.S. The report covers three regions (the producing area, the east consuming region, and the west consuming region) as well as national totals. AGA's regions are shown in Exhibit I-2. AGA calculates the percent of the total working gas remaining in storage for the reporting companies and extrapolates this percentage to all of the U.S. storage facilities. So far, there appears to be a reasonable correlation between these reports and those of the DOE/EIA. The DOE/EIA monthly data are reported from a larger sample of storage operators.

Exhibit I-3 provides a summary of AGA weekly working gas volumes in storage for the three AGA regions and the U.S. total. Although the working gas volumes did not bottom out and peak in exactly the same week during 1994, the regional patterns are very similar. Storage gas reaches a minimum volume in March or early April when withdrawals are ending and peaks in November before the winter season withdrawal begins.

\section{Modeling of Peak Shaving Gas Supplies}

\section{Regional Economics of Peak Shaving}

As described in Chapter VI of the January 1996 Final Report for Task 2 of this project, peak shaving gas supplies are not the economic choice for incremental capacity to meet peak day gas demand in most regions of the U.S., when compared to underground gas storage. Only the New England, Florida, California, and the Pacific Northwest regions currently show an economic advantage for peak shaving over underground storage. However, peak shaving is used and is being expanded in some regions for 
reasons that are apparently outside of simple economic comparisons. Several definitions of terms should be clarified before proceeding with this discussion of peak shaving.

\section{Definition of Peak Shaving}

A common definition of peak shaving supplies is a supply of gas that an LDC or an end-user can access without depending on a delivery system outside of its own facilities. Thus, a major liquefied natural gas (LNG) storage and regasification facility used to enhance a gas pipeline's delivery capability does not qualify as peak shaving. The only peak shaving supplies of significance in the U.S. are LNG and mixtures of propane and air. Peak shaving supplies are usually expected to last for only three to ten days as supplements to other larger supply sources during periods of peak demand.

In recent years LNG has been the favored peak shaving gas supply as its costs have declined with improved refrigeration processes and equipment efficiencies. Propane/air mixtures have been in declining use for peak shaving and some facilities were being abandoned until the frigid eastern U.S. weather of January 1994 caused some rethinking of the value of these plants. One of the reasons for the decreasing popularity of propane/air is the incompatibility of propane in some uses of natural gas. For example, any significant propane contamination of compressed natural gas (CNG) used for vehicle fuel can result in gradual loss of tank capacity as propane condenses in the tank. In addition, propane/air must be diluted with large amounts of natural gas to be suitable for most gas burners, while LNG can be used undiluted. Despite this trend toward LNG in the selection of peak shaving supplies, those LDCs that have major propane/air facilities are expected to continue using them. A major advantage of propane/air peak shaving is the potential for resupply of propane during the winter, while only the LNG storage supplied by LNG imports can be recharged in winter.

\section{Justification of Peak Shaving Investments}

Despite the fact that current comparisons show peak shaving to be economically inferior to underground storage in all but four regions of the U.S., existing peak shaving facilities continue to be used each winter and additional capacity is being constructed in the eastern U.S. A very large part of the justification of peak shaving for LDCs has to be the added confidence obtained by having what amounts to an emergency supply of gas within their own control. Peak shaving supplies represent an insurance policy for the coldest winter nights. This policy is important because interruption of supply to residential and commercial customers is taken as a very serious failure of a gas utility's obligation to serve, by their public service commissions, as well as the affected customers. The public relations costs and renewal of service costs for interrupted customers are not included in the economic comparisons made here for peak shaving vs. underground storage.

\section{Model Assumptions for Peak Shaving Supplies}

Peak shaving supplies are not modeled in the gas storage module of GSAM for two reasons. First, GSAM is currently not structured to include a peak period of three to ten days duration (a third season) that is necessary to perform the economic evaluation of peaking versus other supply alternatives. This short season is necessary for evaluation of peak shaving economics because the relatively low investment cost and higher operating costs of peak shaving typically provide lower cost gas than storage does for only a few days of each winter. The second reason is that, in most consuming regions, peak shaving does not appear to be economically superior to storage, even for short time periods.

To account for the fact that both LNG and propane/air peak shaving is practiced for small volumes of gas supply in several consuming regions, the integrating module of GSAM has been designed 
to include the use of peak shaving gas volumes each winter. Only those regions that currently have peak shaving facilities are forecast to have peaking capacity in the future, and the only regions that are forecast to have peaking growth are those with announced projects. Since the use of peak shaving capacity can vary from zero to 100 percent from year to year, the annual use of peak shaving gas in each region is assumed to be 50 percent of the peaking capacity in the region. The Middle Atlantic region, which has the greatest peak shaving capacity of the 15 consuming regions, can store only 1.3 percent of its current gas demand for residential, commercial, and industrial customers. The highest percentage of supply represented by peaking capacity is in New England, at 1.8 percent of gas demand, for these same three consuming sectors. Thus, peaking supplies are not a large part of total North American gas supply and should not be expected to have much influence on the use of underground gas storage. A summary of the peaking volumes used in the model is provided in Table I-1.

TABLE I-1

Peak Shaving Gas Use Assumptions

(MMcf per Year)

\begin{tabular}{|l|c|c|r|r|}
\hline \multicolumn{2}{|c|}{ LNG WINTER USE, MMCf } & & & \\
\hline \multicolumn{1}{|c|}{ REGION } & 1995 & 2000 & 2005 & 2010 \\
\hline New England & 4,050 & 5,050 & 5,050 & 5,050 \\
\hline Middle Atlantic & 13,811 & 13,811 & 15,811 & 15,811 \\
\hline South Atlantic & 6,558 & 8,558 & 8,558 & 8,558 \\
\hline Florida & - & - & - & - \\
\hline East South Central & 2,566 & 2,566 & 2,566 & 2,566 \\
\hline East North Central & 4,975 & 4,975 & 4,975 & 4,975 \\
\hline West South Central & - & - & - & - \\
\hline West North Central & 4,312 & 4,312 & 4,312 & 4,312 \\
\hline Mountain 1 & - & - & - & - \\
\hline Mountain 2 & 913 & 913 & 913 & 913 \\
\hline California & - & - & - & - \\
\hline Pacific Northwest & 1,349 & 1,349 & 1,349 & 1,349 \\
\hline Canada-East & 1,142 & 1,142 & 1,142 & 1,142 \\
\hline Canada-West & 300 & 300 & 300 & 300 \\
\hline Mexico-Demand & - & - & - & - \\
\hline & - & & & \\
\hline & & & & \\
\hline \multicolumn{1}{|c|}{ PROPANE/AIR WINTER USE, MMcf } & & \\
\hline REGION & 1995 & 2000 & 2005 & 2010 \\
\hline New England & 664 & 664 & 664 & 664 \\
\hline Middle Atlantic & 453 & 453 & 453 & 453 \\
\hline South Atlantic & 2,368 & 2,368 & 2,368 & 2,368 \\
\hline Florida & 38 & 38 & 38 & 38 \\
\hline East South Central & 547 & 547 & 547 & 547 \\
\hline East North Central & 1,873 & 1,873 & 1,873 & 1,873 \\
\hline West South Central & - & - & - & - \\
\hline West North Central & 2,229 & 2,229 & 2,229 & 2,229 \\
\hline Mountain 1 & 11 & 11 & 11 & 11 \\
\hline Mountain 2 & 56 & 56 & 56 & 56 \\
\hline California & 60 & 60 & 60 & 60 \\
\hline Pacific Northwest & 56 & 56 & 56 & 56 \\
\hline Canada-East & - & - & - & - \\
\hline Canada-West & - & - & - & - \\
\hline Mexico-Demand & - & - & - & - \\
\hline & & & & \\
\hline
\end{tabular}


The forecast costs of peak shaving supplies used by LDCs in all consuming regions that have these facilities are provided in Table I- 2 .

TABLE I-2

Peak Shaving Gas Cost Assumptions

(\$Mcf)

\begin{tabular}{|l|r|r|r|r|}
\hline & \multicolumn{1}{|c|}{1995} & \multicolumn{1}{c|}{2000} & \multicolumn{1}{c|}{2005} & \multicolumn{1}{c|}{2010} \\
\hline LNG & 5.84 & 6.67 & 6.53 & 6.40 \\
\hline Propane/Air & 6.93 & 7.91 & 7.75 & 7.59 \\
\hline
\end{tabular}

\section{E. Regulatory Issues}

\section{Regulatory Jurisdiction}

Most storage facilities have to comply with both FERC and state regulations. In those cases where the stored gas is involved in interstate commerce, FERC certification of the project prior to this development and FERC approval of the tariff is mandatory. In these cases, state and local authority will be limited to such items as approval of the site, environmental controls, safety requirements, and public health considerations. In those cases where gas storage will not be involved in interstate commerce, the state and local authorities would have complete jurisdiction at the level they deem necessary.

\section{Tariff Rates}

Typical rates for gas storage will include both fixed and variable charges that are based on costs of constructing, operating, and maintaining the facility. The fixed monthly charges are normally applied to the total volume of gas storage space reserved and the delivery rate required for gas withdrawals. The variable charges are applied to the volumes of gas injected and withdrawn. Recently, the FERC has approved "market based" rates for a few storage facilities that are considered to be subject to sufficient competition from other storage facilities. Although tariff rates for storage are being discounted now by operators in areas where surplus capacity exists, the tariffs remain the best data source for existing storage service costs.

Regional gas storage rates are currently being updated for the GSAM data base. Weighted averages of the storage rates for one or more storage operators in each region will be used by GSAM in making economic decisions on whether to use storage service or an alternative to meet gas demands.

\section{FERC Order 636}

In April 1992, the Federal Energy Regulatory Commission (FERC) issued Order 636, "Pipeline Service Obligations and Revisions to Regulations Governing Self-Implementing Transportation Under Part 184 of the Commission's Regulations". This order marked the culmination of the restructuring of the natural gas industry.

To summarize the impact of the order, FERC determined that the traditional role of pipelines as gas merchants, purchasing gas at the wellhead and selling it to LDCs at the city-gate, was a hindrance to the development of a competitive gas market. FERC intended to make comparable the transportation of gas sold by pipelines and non-pipelines while maintaining the reliability of service. 
Within this initiative, FERC unbundled storage from the sales and transportation functions of the pipeline. Pipelines with downstream storage could keep it "only to fulfill their obligations with respect to system storage management (load balancing) and "no-notice' transportation." The rule intended for access to facilities to be on an "even, nondiscriminatory basis among all shippers." DOE/EIA has estimated that 80 to 90 percent of interstate working gas capacity will become available to previous pipeline customers under Order $636 .^{3}$

In addition, the FERC encouraged the development of market centers as meeting places for gas purchasers and sellers. As a consequence, pipeline storage took on a new role within the industry. Without storage, the seller needs to find a buyer to receive his supply or else there is no sale. Storage allows market centers to provide intertemporal transportation between buyers and sellers. Some storage was transferred or leased to LDCs, some was leased to end-users who wished to insure an uninterruptible gas supply, and some was purchased by brokers, marketers or others with the intention to capitalize on the changes in market prices.

Under Order 636, pipelines were allowed significant latitude in penalizing shippers whose accounts were out of balance. In many cases, shippers experiencing fluctuating demand can use shortterm storage to maintain balance, and thus avoid penalty.

Order 636 also raised the cost of pipeline transportation for consumers and re-sellers that do not have a steady demand for gas by mandating the straight fixed-variable (SFV) rate design. SFV shifts essentially all the fixed costs of gas transmission to the monthly demand charge for the pipeline capacity reserved. Now the only significant variable cost of transmission service is the compressor fuel used by the pipeline. This cost is typically a small fraction of the total transmission cost. Since the demand charge must be paid every month, regardless of the gas volume transported, shippers with low load factors (with wide variations in gas use) now pay more for gas delivery than when part of the fixed costs were included in the changes for gas actually delivered. This change to SFV rates for pipeline capacity has increased the economic attractiveness of storage use for some shippers - compared to paying the higher demand charges of pipelines. Thus, some shippers have increased their storage capacity to offset reductions in pipeline capacity reservations.

\section{F. Organization of the Report}

Following this introductory section, the report next presents descriptions of the reservoir parameters that are most important for evaluating reservoir performance in gas storage service and the development of the database used for reservoir evaluations. These descriptions are followed by a section addressing the selection of reservoir screening criteria and acceptable ranges for the screening criteria. Next, are discussions of the GSAM modifications that have been made to treat gas storage reservoirs in essentially the same manner as producing reservoirs (with the added ability to consider gas injection), such that their performances will also be sensitive to the same technical, economic, and regulatory forces that affect gas production. This is followed by descriptions and results of GSAM testing against existing storage reservoirs and known storage reservoir prospects, under varying economic and technology scenarios.

\footnotetext{
${ }^{3}$ EIA. "The Expanding Role of Underground Storage", Natural Gas Monthly, October 1993.
} 


\section{ReServoir Database DeVelopMent}

The development of an underground gas storage facility is dependent on the characteristics of the reservoir in which the gas is to be stored, particularly the porosity, permeability, depth, thickness and aerial extent of the reservoir. Normally, a reservoir which is chosen for storage is one that has demonstrated the ability to contain and flow gas at high rates. The reservoir's geology will set the limits on the maximum field capacity, but can be designed and engineered to produce a specific capacity and deliverability performance from the reservoir. There are three parameters which will dictate the economic and operational development of a storage field for a specified performance: 1) the volume of base (or cushion) gas, 2) the number of wells in the field, and 3) the amount of horsepower needed to drive the compressors for storage gas injection and withdrawal. The Storage Reservoir Performance Module currently uses The Significant Oil and Gas Fields of the United States and The Significant Oil and Gas Pools of Canada databases developed by NRG Associates for the discovered U.S. and Canadian gas reservoirs. In addition, United States Geologic Survey (USGS), AGA, Hart publications and other published data are also used in creating the storage reservoir database.

The Storage Reservoir Performance Module (SRPM) requires certain key reservoir-specific rock and fluid properties in order to predict deliverability, working gas volumes and cost factors depending upon various technology and costing algorithms. It handles intra-reservoir properties by utilizing pay grades within the reservoir, which take into account the heterogeneity present. These values, in addition to other key parameters (e.g. base gas requirements, location, injection and extraction rates, projected life of the storage reservoir etc.), are sent to the GSAM Demand and Integrating (D\&I) Module. The D\&I module is a linear programming (LP) model which selects the most economical existing and potential new storage reservoirs to meet the gas demand in the electric power generation, industrial, commercial and residential sectors for specified market condition ${ }^{4}$.

The storage database development was divided into two separate subtasks, addressing: a) existing storage facilities and, b) new/potential storage facilities in depleted gas reservoirs.

\section{A. Database For Existing Gas Storage Reservoirs}

There are two reasons why a comprehensive, reservoir-based, database was developed for the existing gas storage reservoirs of the U.S. Most importantly, the database was used to screen storage reservoirs for the improvements in performance and economics that could result from technology advancements. Overall increases in reservoir deliverability in coming years, for example, will come from improvements to existing reservoirs as well as from the development of new storage facilities. GSAM compares the costs and benefits of expanding existing storage with those of new storage in the process of selecting the more economic storage capacity additions. The second need for this database was for use in validating the model. The model was tested by simulating the performance of several existing gas storage reservoirs of each type and adjusting reservoir parameters until the model reasonably predicted the actual performance of these reservoirs.

\footnotetext{
${ }^{4}$ The integrating LP is based on the concept of maximizing producer plus consumer surplus to create estimates of market equilibrium prices and quantities of gas.
} 


\section{The Important Reservoir Parameters}

For evaluation of storage prospects, the storage performance module requires the following 12 data elements for each reservoir examined.

1. Field and Formation Name

2. Location of Field: State and Region code (see Table II-1)

3. Geologic trap type and play code in United States

4. U.S. Geological Survey (USGS) play notations

5. Reservoir/Volumetric Data
a) Average net pay (ft),
b) Reservoir area (acres),
c) Porosity (fraction),
d) Permeability (md),
e) Initial gas and water saturations,
f) Gas gravity,
g) Depth of formation ( $\mathrm{ft}$ ),
h) Original reservoir pressure (psia).

6. Storage Specific data (if available for existing fields)
a) Working gas (MMCF),
b) Base gas (MMCF),
c) Ultimate storage capacity (MMCF),
d) Designed maximum deliverability (MMCF),
e) Horsepower requirements (HP).

7. Well data
a) Number of existing injection/withdrawal (I/W) wells,
b) Number of pressure control/observation wells,
c) Well radius $(\mathrm{ft})$.

8. Other data
a) Type of water influx (strong/medium/weak),
b) Aquifer pressure, where data exists,
c) Fracture matrix permeability (where different from reservoir permeability),
d) Estimated length of fractures. 
TABLE H-1

GSAM/SRPM Region Identification

\begin{tabular}{|c|l|}
\hline $\begin{array}{c}\text { GSAM/SRPM } \\
\text { Region Code }\end{array}$ & \multicolumn{1}{|c|}{$\begin{array}{l}\text { GSAM/SRPM } \\
\text { Region Name }\end{array}$} \\
\hline 01 & New England \\
\hline 02 & Middle Atlantic \\
\hline 03 & South Atlantic \\
\hline 04 & Florida \\
\hline 05 & East South Central \\
\hline 06 & East North Central \\
\hline 07 & West South Central \\
\hline 08 & West North Central \\
\hline 09 & Mountain 1 (South) \\
\hline 10 & Mountain 2 (North) \\
\hline 11 & California \\
\hline 12 & Pacific Northwest \\
\hline 13 & Canada-East \\
\hline 14 & Canada-West \\
\hline 15 & Mexico-Demand \\
\hline
\end{tabular}

\section{Acquisition of Reservoir Data}

Figure II-1 describes the procedure for developing the reservoir specific data on storage prospects used in SRPM. The major source of the data was the AGA database of storage fields which was last updated in 1993. ${ }^{5}$ This AGA database contains certain storage specific information (e.g. working gas, base gas, and deliverability values etc.) but does not contain the detailed reservoir properties in order to predict the future development of the project based on advanced technologies and future expansion using SRPM. In order to achieve this goal, AGA database was cross-walked with the reservoirs identified as existing storage reservoirs by NRG Associates in The Significant Oil and Gas Fields of the United States. The NRG database was used to extract detailed reservoir properties required to solve fluid flow equations in SRPM. Of the 388 reservoirs in AGA database, only 42 reservoirs were found in the NRG database and relevant data was extracted for these reservoirs.

Most of the existing gas storage reservoirs were not included in the NRG database, because they were not producing reservoirs when this database was compiled. Consequently, many of the database elements for existing storage reservoirs had to be developed by questioning operating company representatives for these storage facilities and by using reservoir parameters from appropriately selected nearby producing reservoirs that are included in the NRG database. In developing the appropriate parameters for existing storage reservoirs, data provided in the 1993 AGA report on underground gas storage were used to select comparable reservoirs located nearby. Characteristics of the comparable reservoirs were used as proxies for the required data not provided by AGA. The useful data elements listed (but not always provided) in the AGA report are shown below:

\footnotetext{
${ }^{5}$ American Gas Association, Operating Section Report, "1993 Survey of Underground Gas Storage Facilities in the United States and Canada."
} 
- Reservoir name

- County and state location

- Reservoir discovery year

- Formation name

- Average reservoir pay thickness

- Type of geologic trap

- Reservoir maximum and minimum depths

- Original reservoir pressure
- Reservoir acreage

- Number of output/input wells

- Original reserves

- Developed storage capacity

- Undeveloped storage capacity

- Designed maximum deliverability

- Maximum storage pressure

FIGURE II-1

Development Procedure for the Reservoir Database

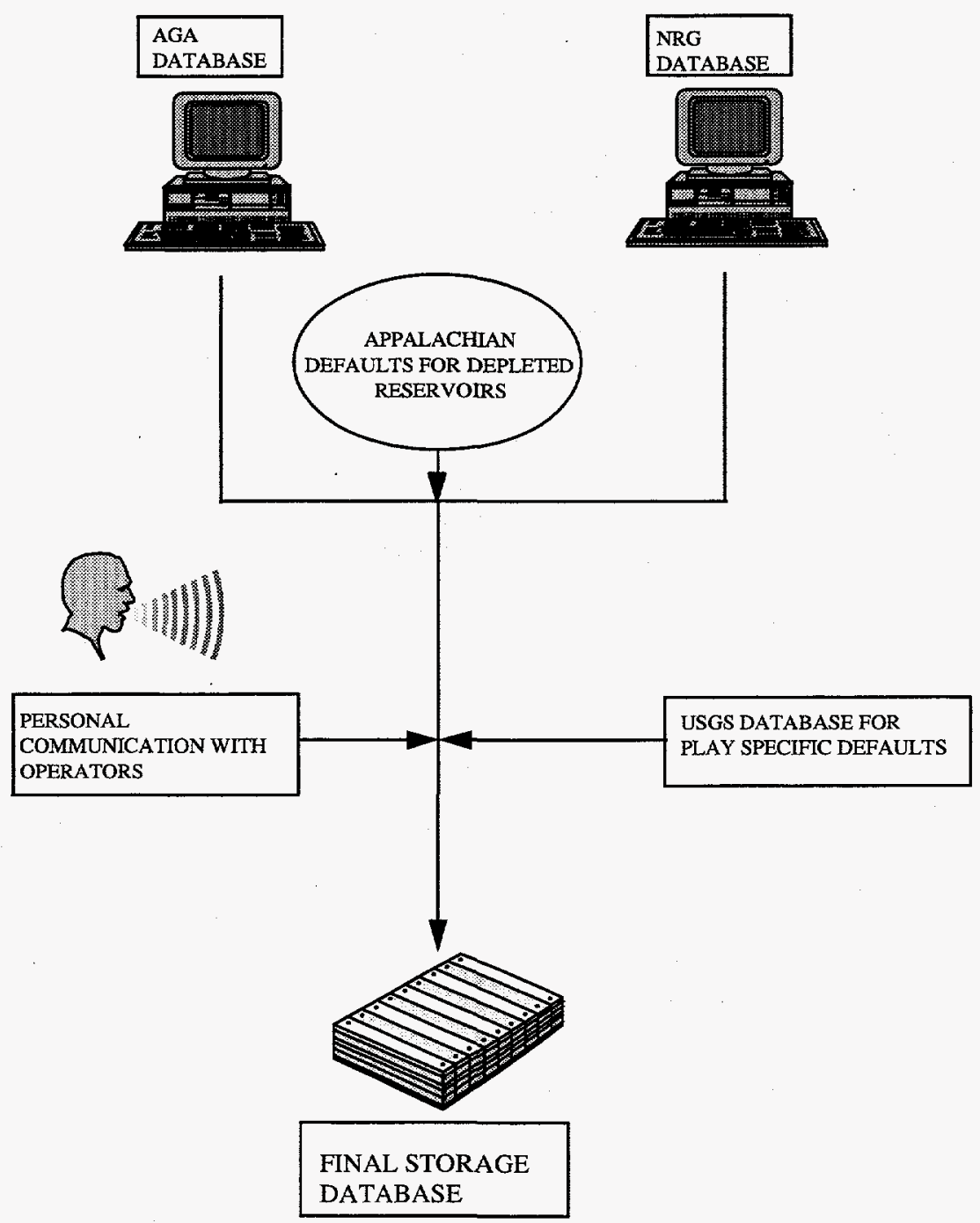


In another exercise, each existing storage reservoir was assigned a USGS geologic play code based on its geology, rock type and location. This code was helpful in assigning play-specific average properties to all reservoirs within the same geologic play. Each reservoir in the storage database was assigned a 11 digit code (defined as Storage ID) based on its regional location, reservoir type, play code and unique AGA identification number. This NRG proxy data approach and the USGS play approach was not possible for existing aquifer and salt cavern storage facilities nor for depleted reservoirs in the Appalachian basin, because they are not included in the NRG databases for gas and oil reservoirs. For these three cases, data sources were limited to the AGA report, contacts with storage facility operators, internal knowledge at ICF Resources, and other published materials.

\section{B. Database For New/Potential Storage Reservoirs}

The new dynamics of the natural gas market has created significant additional interest in construction of new storage facilities. Substantial projected growth in short-term summer gas use by the electric generation sector in the Mid-Atlantic, South Atlantic, East South Central and West North Central regions suggests a potential need for high deliverability storage in these regions. Most of the potential storage projects would be depleted gas reservoirs located near to the demand regions. In this exercise, therefore, the depleted gas reservoirs were considered for database development.

\section{The NRG Reservoir Database}

Since the NRG database for gas and oil reservoirs already resided in GSAM, much of the data required for evaluating gas and oil reservoirs for suitability as future gas storage reservoirs were readily available. The NRG database contains over 180 elements of data for each reservoir in its database. The data elements included in this database are reservoir properties, location, production histories etc. among other items. In those cases where critical data elements were missing for a reservoir, default values were estimated either by developing default equations or by selecting data through comparisons with appropriately similar nearby reservoirs. The NRG database consists of several thousand gas reservoirs which could be candidate for storage. Various screening criteria were utilized to select the ideal candidate for storage reservoirs. Altogether around 140 potentially new storage reservoirs were included in the database.

\section{The Appalachian Reservoir Database}

The Appalachian atlas of oil and gas reservoirs that was originally scheduled to be available for use in the selection of new storage reservoirs was delayed and was unavailable for use in this project. Since no other comprehensive data source was made available, the characteristics of potential storage reservoirs for the eastern U.S. was generated from a cross-section of the eastern U.S. existing storage reservoirs. Many of the Appalachian storage prospects have been studied for several years and their characteristics are well known among geologists and petroleum engineers who have specialized in gas storage in the eastern states. Without this approach, no GSAM analysis of storage prospects in Appalachia could be made. ${ }^{6}$

The database developed for the eastern U.S. includes around 10 reservoirs for most of the Appalachian states including Ohio, West Virginia, Pennsylvania, and New York. Reservoirs located in USGS plays $6719,6720,6721,6725,6732,6737$ were selected as potential storage sites based on their

\footnotetext{
${ }^{6}$ And in our opinion, this approach was the only viable one for completing the Appalachian database.
} 
reservoir properties, location, and deliverability estimates. Potential storage reservoirs such as two new fields in south central New York (Steuben County), Adrian and Thomas Corners were represented in the database. The potential for new storage reservoirs in north central Appalachia lies within the area of the basin which lies west of the line that extends from Syracuse, NY to Hagerstown, MD. Geology to the east of this boundary is mostly Cambrian and granite type rocks that don't have the reservoir characteristics of porosity and permeability for good storage. Altogether 50 storage reservoirs were found to be potential storage sites based on the selection criteria as described in Section III of this report. 


\section{RESERVOIR SCREENING FOR STORAGE USE}

\section{A. Technical Screening Criteria for Storage}

Reservoirs in the GSAM database contain significant data on the rock and gas properties for producing reservoirs nationwide. This information, including appropriate defaults to account for missing elements, can be used to screen and evaluate reservoirs for future storage use. This section describes the screening criteria developed based on evaluation of active storage projects. In addition, values for key storage project properties not available from the GSAM database can be estimated based on available data. The procedure described here provides all the necessary information for use in the reservoir performance model described in the next section.

The procedures developed to screen projects and default missing data were developed based on analysis of the American Gas Association (AGA) data on storage projects. Information available on existing projects in this data set were evaluated to determine critical limits to the use of reservoirs of various types as storage projects. Existing storage reservoirs were matched, where possible, to the reservoirs described in the GSAM database. This allowed evaluation of data for a variety of properties and cross checking of entries to ensure consistency. Where data for similar elements did not agree, the data in the AGA data set was assumed to be more accurate for the storage projects.

The critical properties impacting storage project description include permeability, depth, working pressures, and drive mechanisms. Most of this information is contained in the GSAM database for nonassociated gas reservoirs. To determine missing properties from the database or elements not included in the data, several screening procedures and defaults were developed.

The first priority was to eliminate reservoirs that did not have suitable geology or volumes for use as storage sites. For this procedure, information in the GSAM data on Resource Type, Drive Type, and Field Type was used. Only sandstone, limestone, dolomite, and chalk reservoirs were evaluated for storage potential. Strong water drives, where abandonment pressure was more than $75 \%$ of original, were eliminated from consideration as storage candidates. Also, reservoirs with complex settings, as demonstrated by poor recovery (less than $50 \%$ of original gas in place) were dropped as well.

For depleted non-associated gas reservoirs with suitable rock types and recovery history, those with less than $5 \mathrm{BCF}$ original gas in place (OGIP) were eliminated as candidate storage sites. Depleted oil reservoirs where the total original gas and oil in place was less than the equivalent of $5 \mathrm{BCF}$ were also dropped. The original oil in place (OOIP) was converted to equivalent gas in place using the following formula:

$$
\begin{gathered}
\text { OGIP (equivalent) }=\text { OOIP* Boi*0.199* Pressure/ Temperature or } \\
=\text { OOIP } * \text { Boi/Bgi if known }
\end{gathered}
$$

where Boi is the original oil formation volume factor in cubic feet per stock tank barrel and Bgi is the gas formation volume factor in cubic feet per billion standard cubic feet.

Deep reservoirs were selected in such a manner that they were large enough to support the additional costs associated with development and operation of the project. Table III-1 represents minimum reservoir volume by depth criteria used in this study. 


\section{TABLE III-1 \\ Minimum Reservoir Volume by Depth Criteria}

\begin{tabular}{|c|c|}
\hline Depth Range & Minimum Volume \\
\hline $7000-7500$ & $15 \mathrm{BCF}$ \\
\hline $7501-8000$ & $32 \mathrm{BCF}$ \\
\hline $8001-9000$ & $72 \mathrm{BCF}$ \\
\hline $9001-10000$ & $120 \mathrm{BCF}$ \\
\hline $10001-11000$ & $176 \mathrm{BCF}$ \\
\hline $11001-12000$ & $240 \mathrm{BCF}$ \\
\hline
\end{tabular}

Note: Reservoirs deeper than 10,000 feet were eliminated.

In addition to small reservoirs, immature reservoirs; i.e:, those with less than $80 \%$ cumulative recovery of their estimated ultimate reserves, were dropped from the database.

Reservoirs with unacceptable levels of impurities were also eliminated. Based on AGA data, no reservoirs were considered for storage sites if they had $\mathrm{H}_{2} \mathrm{~S}$ in excess of $0.3 \%, \mathrm{CO} 2$ in excess of $6 \%, \mathrm{~N} 2$ in excess of $10 \%$, or total non-hydrocarbon gases in excess of $20 \%$. These limits were used to screen reservoirs and eliminate projects with excessive impurities. Also, the original gas volume limits described above were expanded to account for additional volumes required for the non-hydrocarbon concentrations of each reservoir, including changes in average gas compressibility.

\section{B. Estimation of Missing Storage Reservoir Properties}

Values for storage project for volumetrics, porosity, permeability, depth, and gas characteristics were available from the GSAM database. Where data was not available, GSAM's Resource Modules estimated the missing value based on the geologic play, using engineering calculations. Estimating the volume of working gas and base gas for a reservoir involves determining the storage reservoir working pressure and the volume available for storage. The working pressure was assumed to be the original reservoir pressure. When this was not available, the pressure was estimated based on the reservoir depth using a pressure gradient consistent with the geologic play. Two areas were adjusted to reflect unique pressure relationships. In the Upper Midwest (Michigan, Ilinois, Indiana, etc.) for reservoir less than 5000 feet deep the maximum storage pressure was assumed to be calculated as follows:

$$
\text { Storage Pressure }=\text { Pressure Original } *(1.5-3.33 *(\text { Pressure Original/Depth-0.35) })
$$

Similarly, in Eastern Canada:

$$
\text { Storage Pressure }=\text { Pressure Original } *(1.5-2.67 *(\text { Pressure Original/Depth-0.35) })
$$

The calculated storage working pressure was set to a limit of $110 \%$ of original pressure for all reservoirs. This is the highest reported value for any project in the AGA database. 
Based on the storage working pressure, reservoir volume, and gas characteristics, the total amount of storage capacity, working gas plus base gas, was estimated. The standard volumetric formula as shown below was used to calculate storage capacity:

\section{Storage Capacity $=43560 *$ Area $*$ Thickness * Porosity * Gas Saturation/ \\ Gas Formation Volume Factor}

The gas formation volume factor (Bg) was determined based on the temperature, pressure, gas gravity, and concentration of impurities. This value was estimated based on the storage gas and reservoir conditions as well as the original reservoir gas and other reservoir properties.

\section{Acceptable Ranges for Screening Criteria}

The new/potential storage candidates were selected based on various selection criteria. The NRG database contains several thousand depleted gas reservoirs, which could be candidates for storage facilities. This extensive list was narrowed to 2403 prospects based on total reserves (reservoirs with reserves less than $5 \mathrm{BCF}$, and original gas in place estimates higher than $100 \mathrm{BCF}$, were not selected), depth (reservoirs with depth greater than 10,000 ft were not selected), and location (Alaska and Offshore reservoirs were not selected). Once this list was formed, it was run through various screening criteria (for example: the initial gas saturation value should always be higher than 0.65 , porosity value should be higher than $10 \%$, permeability value should be higher than $100 \mathrm{md}$. etc.) based on location and size of the reservoir. In addition, separate screening criteria were used for each state to account for their storage needs and availability. Engineering judgment was utilized in some cases to by-pass these screening criteria to accurately represent the potential of future storage reservoirs. One of the most important requirements in selecting a new/potential reservoir was the availability of data for at least 6 to 7 of the identified critical reservoir parameters. These parameters are required to predict deliverability, working gas and base gas value for the storage reservoir. In selection of potential storage facilities, emphasis was given to those fields which were geographically near to the demand regions and therefore would not incur high pipeline transportation costs. 


\section{GSAM MODIFICATIONS}

Gas Systems Analysis Model (GSAM) was developed as a comprehensive, non-proprietary PCbased model with a primary purpose of assessing the impact of supply technology developments on U.S. natural gas supply, and a secondary purpose of assessing various impacts of policy/regulatory initiatives, on U.S. gas markets.

An important aspect of the current GSAM approach is the Reservoir Performance Module, which involves prediction of the technical and economic performance of producing gas reservoirs under various completion and production configurations. It estimates the ultimate recovery and production rates based upon explicit, geologic conditions at the reservoir level, and fundamental reservoir engineering principles using a suite of type curves. It can also assess the impact of alternative technologies on ultimate gas recovery, production, and extraction costs by representing advanced technology practices as explicit usercontrolled changes in the reservoir model or economic parameters. This approach incorporates substantial improvements over traditional approaches to characterizations involving a "percentage increase" in recovery or simplified proxies for technology performance that ignore the variation in impact across the resource base. Costs for each reservoir are estimated at the same level of detail considered by an operator. Capital, operating and environmental compliance costs are calculated based on region, resource type, regulatory conditions, depth, production rates, and technology characteristics.

However, in its current configuration, GSAM uses an aggregated approach to characterize and predict the performance of gas storage facilities. GSAM represents storage of gas in material balance constraints that balance the supply and demand of gas for each region, time, and season. The various storage costs and other parameters are, however, at the regional level.

In the current task, ICF Resources modified GSAM to allow for a more rigorous modeling of gas storage. The storage data was built from a database of actual storage sites. In particular, a Storage Performance Module was developed to predict the performance and costs of each individual gas storage reservoir. These data are then passed on to the Demand and Integrating Module, which incorporates these disaggregated results in balancing supply and demand for gas, and for determining market equilibrium prices and quantities of gas. The enhancements also included the capability to calculate the changing cost of additional storage capacity as new storage demands are realized and as new technologies reduce costs or improve capacity or deliverability.

\section{A. Purpose of GSAM Modifications}

In modifying GSAM for this project, the goal was to clearly identify storage facility types and specific, concrete technology improvements that DOE could consider in developing its gas storage R\&D. The current task aims to incorporate a first-level geologic model with a fairly comprehensive "cost-todevelop" analysis to determine the suitability of each candidate as a storage reservoir. The model will do this within the context of the entire gas market system, recognizing the potential for alternatives to storage to become more attractive if storage costs rise. The following enhancements to the capabilities of GSAM have been made as a result of this research through modifications to its existing features:

- Screen economically depleted gas and oil reservoirs for technical, environmental and gross economic suitability as storage reservoirs.

- Screen existing storage reservoirs for their suitability for expansion in size or deliverability rate. 
- Determine the cost of storage development for a given economic and technology scenario, the expected performance of the project, and the resulting cost of service to storage customers.

\section{B. Individual Modifications to GSAM}

Modifications to GSAM focused on the following changes:

- Modify the gas reservoir production and ultimate recovery routines to predict both gas injectivity and deliverability in storage reservoirs.

- Modify the operating cost algorithms to predict compression, injection, production and processing costs over time in gas storage projects.

- Modify the reservoir performance type curves to allow for prediction of injection into and flow from depleted gas and oil reservoirs, and aquifers.

- Add injection and production performance relationships for salt caverns.

- Develop new technology/performance/cost relationships for technologies with the highest potential impact on storage reservoir development.

- Modify the economics module to permit the evaluation of gas storage capital costs and injection/production costs, as well as an income stream based on service charges related to storage. Also, modify the income and severance tax treatments accordingly.

- Modify the Demand and Integrating (D\&I) Module of GSAM to incorporate storage reservoir level data in balancing supply and demand of gas.

\section{Modeling Methodology of Storage Reservoir Performance Module (SRPM)}

The Storage Reservoir Performance Module was derived from the Reservoir Performance Module of GSAM, which estimates production rate and ultimate recovery of gas as a function of reservoir characteristics and technology assumptions. It utilizes a suite of engineering type curves, modified from evaluation methods used in classical well test analysis, that can handle conventional, aquifers, and salt dome cavern reservoirs. SRPM has been developed to predict both gas injectivity and deliverability from storage reservoirs, and hence the type curves have been modified accordingly. To explain the workings of the type curves in SRPM, the following radial flow equation (Darcy's law), and the mass balance equation are shown which provide an idea into the calculations such as the injection/withdrawal rate, and the working and base gas estimates (technically recoverable reserves) from the storage reservoir:

$$
Q=\frac{0.703 k h\left(p_{c}^{2}-p_{w f}^{2}\right)}{T \mu Z\left[\ln \left(\frac{r_{e}}{r_{w}}\right)-0.75+s+D_{q_{s}}\right]}
$$

where,

$\mathrm{Q} \quad=$ the flow rate in MMCF/Day,

$\mathrm{k}=$ the permeability of the reservoir in md,

$\mathrm{h} \quad=$ the reservoir thickness in $\mathrm{ft}$,

$P_{c} \quad=$ the average reservoir pressure in psia, 


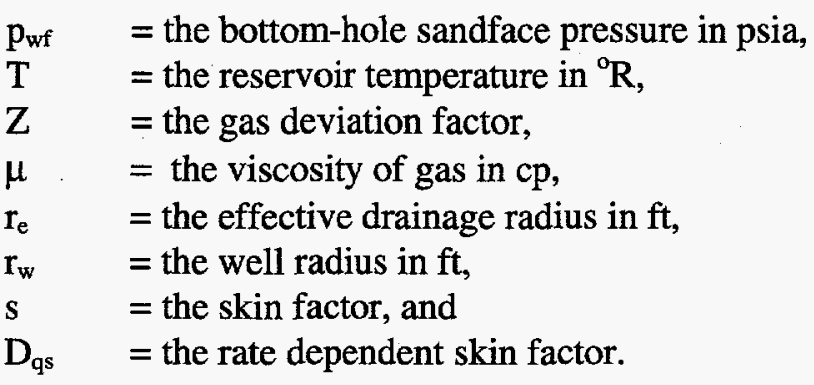

The flow equation (1) predicts the gas flow rate such that the mass balance in the reservoir is satisfied. The following mass balance equation is used in SRPM:

(2) $G_{p} B_{g f}=G\left(B_{g f}-B_{g i}\right)+W_{e}-B_{w} W_{p}$

where, $G_{p}$ is the cumulative gas produced in $B C F, B_{g f}$ is the gas formation volume factor (bbl/SCF) at the end of the time step, $\mathrm{G}$ is the original gas in place in $\mathrm{BCF}, \mathrm{B}_{\mathrm{gi}}$ is the gas formation volume factor (bbl/SCF) at start of the time step, $W_{e}$ is water influx during the time step in $b b l, B_{w}$ is water formation volume factor in $\mathrm{bbl} / \mathrm{STB}$, and $\mathrm{W}_{\mathrm{p}}$ is water produced during the time step in STB. The flow equation (1) and the mass balance equation (2) form the iterative loop and a solution is found when pressures and flow rates converge for all the time steps.

As explained earlier, the Reservoir Performance Module of GSAM was developed with the purpose of estimating production rate and ultimate recovery for a gas reservoir produced to its economic limit. Storage facilities, on the contrary, go through alternating production (withdrawal) and injection (refill) periods. Thus, one storage cycle consists of a production phase where gas is withdrawn to meet the demand, and an injection phase where the reservoir is refilled. At the end of each complete cycle, the reservoir is restored to its original condition in terms of reservoir pressure and gas-in-place. This can only be achieved by designing the injection phase in each cycle based on the production (withdrawal) phase performance.

\section{Modification of GSAM's Operating Routines to Allow Gas Withdrawal/Injection}

The following key modifications/additions were implemented to adapt the GSAM Reservoir Performance Module to evaluate storage reservoirs:

1. Different and variable time step sizes were implemented for the withdrawal and injection periods;

2. Type-curve analysis routines were tailored to calculate injection rate requirements at succeeding time steps based on the total gas withdrawn during the preceding time step;

3. As each complete storage cycle (withdrawal + injection) involves two time steps, a routine was added to convert performance in each time step to an annualized basis for economic calculations; and

4. Assumptions/enhancements specific to the type of reservoir, i.e., depleted gas reservoir, aquifer or salt dome cavern, were incorporated.

A detailed description of each of these additions and modifications follows. 


\section{Time Step Sizes}

The time step sizes for the withdrawal and injection phases in a storage cycle are equal to the actual withdrawal and injection times respectively. Industry standard factors were used to determine the injection time requirement based on the withdrawal time. For example, if the withdrawal time was 3 months and a factor of 1.5 was used, the injection time would be 4.5 months. In actual computations, 100 days of withdrawal and 265 days of injection were assumed simulating base load storage facilities. These values were used because SRPM primarily provides input to the Demand and Integrating (D\&I) module of GSAM where storage is competing with pipeline construction for transporting gas and thus storage is considered a base load option. Hence, for the purpose of the integrating linear program the D\&I module searches for the least costly alternative. SRPM is designed, however, to analyze all alternative development profiles including peaking for a particular storage facility whenever not running in an integrated manner.

\section{Injection Calculations}

The injection rate was calculated for each alternating time step corresponding to the injection phase of the storage cycle using the following equation:

$$
\text { Injection Rate }(t)=\frac{\text { Total Gas Withdrawal }(t-1)}{\text { Injection Cycle Time Step Size }}
$$

Where $t$ is the index for the time step.

The steps involved in the rate/pressure calculations were also modified to enable calculation in SRPM. The modified calculation procedure was as follows:

1. Calculate the withdrawal rate and pressure for a given production time step.

2. Calculate the average reservoir pressure at the end of the time step.

3. Calculate the total gas produced during the withdrawal cycle.

4. Calculate the injection rate based on the total gas produced during the production cycle.

5. Calculate the reservoir pressure after the injection period using dimensionless type curves.

6. Repeat steps 1 through 5 for the number of storage cycles in each analysis.

\section{Conversion of Time Step Sizes to an Annual Basis}

SRPM calculates production and injection quantities for each storage reservoir based on production and injection cycle times. These times are not necessarily expressed on an annual basis and therefore must be converted appropriately for annual accounting and calculations. SRPM was adjusted to convert production and injection cycles into discrete calendar timesteps. The model then converted the timesteps into annual values for use in costing, economics and discounted cash flow evaluations. To clarify this point consider the following illustrative example for three years, with the production 
(withdrawal) cycle equal to 0.1 years and the injection cycle equal to 1.0 year (10 times the production cycle). Note that the following pattern of production and injection cycles are maintained:

1. Production cycle \#1, Followed by Injection cycle \#1;

2. Production cycle \#2, Followed by Injection cycle \#2;

3. Production cycle \#3, Followed by Injection cycle \#3.

\begin{tabular}{|c|c|c|}
\hline $\begin{array}{l}\text { Time } \\
\text { (Year) }\end{array}$ & Withdrawal Activity & Injection Activity \\
\hline $\begin{array}{l}0.0 \\
0.1 \\
1.0\end{array}$ & $\begin{array}{l}\text { Production cycle \#1 Started } \\
\text { Production cycle \#1 Completed }\end{array}$ & $\begin{array}{ll}\text { Inj. cycle \#1 } & \text { Started } \\
0.9 \text { Injection cycle \#1 } & \text { Completed }\end{array}$ \\
\hline $\begin{array}{l}1.1 \\
1.2 \\
2.0\end{array}$ & $\begin{array}{l}\text { Production cycle \#2 Started } \\
\text { Production cycle \#2 Completed }\end{array}$ & $\begin{array}{ll}0.1 \text { Injection cycle \#1 Completed } & \text { Complarted } \\
\text { Inj. cycle \#2 } & \text { Starled } \\
0.8 \text { Injection cycle \#2 Completed }\end{array}$ \\
\hline $\begin{array}{l}2.2 \\
2.3 \\
3.0\end{array}$ & $\begin{array}{l}\text { Production cycle \#3 Started } \\
\text { Production cycle \#3 Completed }\end{array}$ & $\begin{array}{ll}0.2 \text { Inj. cycle \#2 } & \text { Completed } \\
\text { Injection cycle \#3 } & \text { Started } \\
0.7 \text { Injection cycle \#3 } & \text { Completed }\end{array}$ \\
\hline
\end{tabular}

From the above table we can see that the annual amounts are as follows:

\begin{tabular}{|l|l|l|}
\hline $\begin{array}{l}\text { Time } \\
\text { (Year) }\end{array}$ & Withdrawal Activity & Injection Activity \\
\hline 1.0 & $100 \%$ of Production cycle \#1 & $90 \%$ of Injection cycle \#1 \\
\hline 2.0 & $100 \%$ of Production cycle \#2 & $\begin{array}{l}10 \% \text { of Injection cycle \#1 + } \\
80 \% \text { of Injection cycle \#2 }\end{array}$ \\
\hline 3.0 & $100 \%$ of Production cycle \#3 & $\begin{array}{l}20 \% \text { of Injection cycle \#2 + } \\
70 \% \text { of Injection cycle \#3 }\end{array}$ \\
\hline
\end{tabular}

SRPM was developed to allow the withdrawal and injection cycles to take values greater than, less than, or equal to one year. Hence, SRPM can be run in full production mode or in storage (withdrawal + injection) mode depending upon the time steps designed.

\section{E. Modification of the Reservoir Performance Module of GSAM}

Some key assumptions and reservoir type specific modifications were also incorporated into the model to address differing input requirements and technology specific information. These changes were determined by calibrating and testing the model for different reservoir types.

\section{Depleted Gas Reservoirs:}

- the reservoir when filled was assumed to be at its initial conditions of pressure and gas saturation;

- $20 \%$ of the wells located in the reservoir were stimulated every year to maintain constant deliverability;

- an injection efficiency of $95 \%$ was used to account for leakage and injection losses;

- the variation of permeability among different pay grades was kept within $\pm 25 \%$;

- a tubing size of 5 inches was used for deliverability and injectivity calculations. 
Aquifers (Water Drive Reservoirs):

- the aquifer underlying the storage reservoir was assumed to be five times larger than the storage reservoir volume;

- the reservoir when filled was assumed to be at its initial conditions for pressure and gas saturation;

- $20 \%$ of the wells located in the reservoir were stimulated every year to maintain constant deliverability;

- an injection efficiency of $95 \%$ was used to account for leakage and injection losses;

- the variation of permeability among different pay grades was kept within $\pm 25 \%$;

- a tubing size of 5 inches was used for deliverability and injectivity calculations.

\section{Salt Cavern Reservoirs:}

- the salt cavern was modeled as a depleted gas reservoir with very high permeability and porosity;

- the cavern was assumed to be at its initial conditions;

- the cavern was reworked every alternate year;

- an injection efficiency of $95 \%$ was used to account for leakage and injection losses;

- a tubing size of 6.5 inches was used for deliverability and injectivity calculations.

\section{F. New Technology Performance and Cost Relationships}

\section{Storage Cost Evaluation}

The modification of the GSAM gas reservoir type curve modules provided estimates of withdrawal and injection volumes, number of wells in storage service, operating pressures, and other storage performance parameters. In addition, economic analysis subroutines were updated and modified to conform to storage investment decision criteria. These modules use input data on specific regional and national costs to generate discounted cash flow (DCF) assessments of specific projects. The costs are tied to selected performance characteristics and can be varied based on the technologies being employed.

Initial estimates of costs for drilling investments, completion costs, workovers, fixed and variable operating costs, and compression installation, maintenance, and operation were first developed. As explained earlier, the Storage Reservoir Performance Module uses a slightly modified approach from GSAM. The input costs for regional drilling and completion are the same. Operating costs can be varied regionally and are based on the depth, injection and withdrawal rates, and operating conditions. Compression requirements are determined based on the brake-horsepower requirements to meet pipeline pressure requirements during storage withdrawal and to sustain adequate injection during the summer.

Based on the estimates developed for specific investments and costs, expenditures over time were determined based on the development/conversion phasing of the project. Also, future annual investments and maintenance requirements were determined for specific periods of service. These annual costs were computed based on the estimated storage performance determined in the type curve routines. Based on the fully developed project timing, the DCF for the project was determined based on the revenues generated from gas sales and rents. These estimates were developed using detailed project cash flow analysis, with contemporary, specific state and federal tax rates and deductions.

The Storage Reservoir Performance Module also does a series of DCF calculations to determine the sensitivity of the potential storage projects to changes in economics. The evaluations consider the impact of changes in gas prices, drilling costs, other required investments, taxes, and other costs. This series of analytical results provide a range of economic outcomes that can be tailored to estimate results 
under varying future market conditions. This provides details needed in the GSAM Demand and Integrating Module for individual project decisions. The process of selecting projects based on their economic attractiveness is described below.

\section{Technology Evaluations}

Changes in a variety of development and operating practices can be modeled for storage projects. The Storage Reservoir Performance Module provides the capability to independently assess the impacts of performance enhancements and cost savings on the overall project economics for individual storage sites. This analysis can provide a wide variety of results for $R \& D$ analysis.

Direct storage performance improvements can be modeled by changing the completion design and gathering system pressure. Improvements in operating practices and workover designs can dramatically improve the near wellbore damage associated with storage operations. This is modeled by changes in the skin factor restricting or enhancing flow in the near wellbore region. Horizontal wells with varying lateral lengths can also be directly modeled for storage applications. Technology improvements in well design, using improved tubing and completion practices can also be modeled by changing the production tubing diameter and/or the well bore radius. This reflects the improved flow capacity from larger radius drilling and completion technology. In addition, the flowing tubing pressure is directly determined based on the roughness associated with various materials. The system pressure to which the well produces can also be altered to reflect expanded or improved compressor design.

Economic impacts of storage technology improvements can be modeled through the detailed variation of individual project costs. Investments, remediation costs, and standard operating expenditures can be impacted directly or indirectly by technology changes. The Storage Performance Module independently assesses the changes in costs associated with the application of new technologies. For example, horizontal drilling will improve storage injectivity and possibly reduce the number of wells required for many storage sites, however, individual horizontal wells will cost 40 to $100 \%$ more than conventional, vertical wells with standard completions. Improved monitoring of storage pressures could ultimately reduce operating costs and reduce losses. This type of technology improvement can also be directly assessed.

The greatest value of the newly designed system is the capability of evaluating multiple technology improvements consistently and simultaneously. This provides the ability to evaluate the relative value of various technology improvements and to assess the synergistic impact of application of two or more technologies in combination. For example, the development of storage with horizontal wells combined with the improved compressor efficiency to lower producing pressures and costs could have a larger impact than either application alone. Further, because reservoirs are uniquely described based on their storage project properties, analysis can focus on the resources with the greatest potential for future success. The evaluation of storage in a market dynamic model assures that R\&D planning evaluations will provide meaningful, market-required information.

\section{Technology Evaluation Suggestions}

The initial evaluation of storage technology should reflect changes that could result from FETC and industry R\&D. Based on evaluations using GSAM, technologies that reduce drilling costs, utilize horizontal wells, decrease wellbore damage (skin), and optimize compression should have the largest impact in the future, market-driven natural gas system. The analysis here will focus on these technologies. 
Consistent with emerging technologies, horizontal wells will be used in candidate storage reservoirs where the thickness and overall size are sufficient to allow their drilling. With advances in technology, horizontal wells with lateral of 3000 feet should be possible at a cost of $20 \%$ more than vertical wells. In addition, improved drilling muds and bits will allow completions with less formation damage, reducing skin factors by $50 \%$.

Compressor efficiency should improve allowing smaller more efficient compressors to move gas to and from storage. The reduction in required brake-horsepower will be evaluated on a reservoir specific basis. The average operating cost of storage will also decline over time with advances in metering and computer-aided production systems. This will reduce variable and fixed operating costs by up to $20 \%$.

Combinations of drilling, completion, compression, and operating costs will be evaluated to determine their combined impacts. Further, the relative impacts of technology advances by industry, GRI, and FETC will be estimated. Based on the findings, key shortcomings of storage availability will be determined.

\section{G. Modifications to Cost Routines}

After the type curve analysis has been completed, SRPM calls for various programs to perform a detailed cash flow analysis. The purpose of this calculation is to evaluate production and operating costs under all reasonable economic conditions. The process of detailed cost and economic analysis as done in SRPM is as follows:

(1) Unit Cost Calculations: Compute stimulation cost, development drilling costs, facilities cost, fixed and variable $O \& M$ costs. All values are calculated on a unit cost basis (\$/well, \$/Mcf, etc).

(2) Costing Algorithms: Calculate total cost based on the number of wells available for gas storage and production rate. The costs calculated include total drilling cost, total stimulation cost, total compressor cost, total facilities cost, and total fixed and variable operating costs. The algorithm also evaluates the total levelized investment cost, fixed operating cost and variable operating cost for every unit of gas produced during a year cycle. The output serves as a input for GSAM's DRI module.

(3) Final Cash Flow Algorithm: This section computes the detailed pro-forma cash flow for each reservoir, including full cost accounting and tax calculations for further studies. Based on the results of this section, a discounted cash flow analysis is conducted to calculate the cost of service for a new storage field.

For existing storage reservoirs the costs of service for storage reservoirs is based on the tariff rates of the company that operates the reservoir. Various independent surveys and informal discussions with gas storage operators were conducted to determine the levelized, operating and fuel costs and were incorporated in SRPM.

Most of the modifications made to the GSAM economic module were incorporated in the above routines to reflect storage costs and other economic parameters. The costing algorithms were derived from various sources and are widely used in industry for designing new storage facilities. 


\section{H. Working of SRPM}

SRPM includes reservoir data for both existing and undeveloped storage facilities. Since it has reservoir specific entries for each of its 388 existing and around 140 potential storage sites, it is capable of performing assessments of the technical and economic potential of numerous storage prospects rapidly. Effects of better fractures, horizontal wells, better drilling fluids, environmental regulations etc. can be characterized using SRPM since it operates on the reservoir level. Hence, this is an effective planning tool for the FETC in deciding its research and development needs for gas storage.

SRPM evaluates the existing and undeveloped storage reservoirs differently because of the availability of data.

\section{A. Existing Storage Facilities}

For existing storage sites the AGA database provides the working gas, base gas, and deliverability values. The AGA database, however, doesn't include the reservoir rock and fluid properties. SRPM performs history check calculations as shown in Figure IV-1, and adjusts the skin factor and permeability values so that the calculated deliverability is close to the reported deliverability. This is required for technology modeling of existing reservoirs. In this way SRPM computes the permeability and skin factors for all 388 existing storage reservoirs having reported deliverability values from AGA. SRPM then performs economic calculations and performs an after-tax pro-forma cash flow analysis for every reservoir analyzed. The modified economic module of SRPM provides levelized investment costs, fixed and variable O\&M and fuel usage values for GSAM's Demand and Integrating Module to incorporate into the linear program for storage applicability and expansion efforts in a full market context.

\section{B. Potential New Storage Facilities}

SRPM evaluates the undeveloped storage facilities in a different manner than from what was explained earlier. Here, all the reservoir properties are available from NRG, and USGS databases and hence no history check is performed. Based on the screening criteria developed, around 140 depleted gas reservoirs have been selected as potential storage candidates in this category.

For these reservoirs, values for base gas, working gas and deliverability have to calculated. The type curve approach utilized in SRPM provides the capability of designing the storage facility based on the economics and particular storage needs.

Figure IV-2 shows the model workings in calculating the deliverability. Since storage is designed for deliverability of the last MCF of working gas needed, it is essential to determine the maximum withdrawal rate that can be achieved at the end of the withdrawal cycle. In SRPM, gas is withdrawn from the reservoir at a defined proration and a design minimum flowing wellhead surface pressure for the full withdrawal cycle. In most cases, SRPM utilizes a design minimum flowing wellhead pressure of 100 psia and 100 days for withdrawal cycle. As shown in Figure IV-2, at first the gas is withdrawn at a rate of R1 MCF/Day. During the withdrawal cycle of 100 days, the rate declines as indicated. At the end of 100 days, the withdrawal rate $\mathrm{R}^{\prime}$ ' is obtained which is considerably lower than $\mathrm{R} 1$. This reservoir can be designed for a deliverability of R1', however, it is capable of producing at a higher rate than R1' for its entire withdrawal cycle. Hence, a design deliverability of R1' for this particular reservoir would not be prudent. In case gas is withdrawn from the reservoir at R2 MCF/Day (R1>R2), the reservoir will sustain a constant rate of $\mathrm{R} 2$ for a longer time compared to $\mathrm{R} 1$ as shown, and would produce at a higher rate than $\mathrm{R} 1$ ' (R1'<R2') at the end of 100 days. SRPM, continues with this exercise until it obtains a constant 
FIGURE IV-1

Flow Chart of SRPM Process

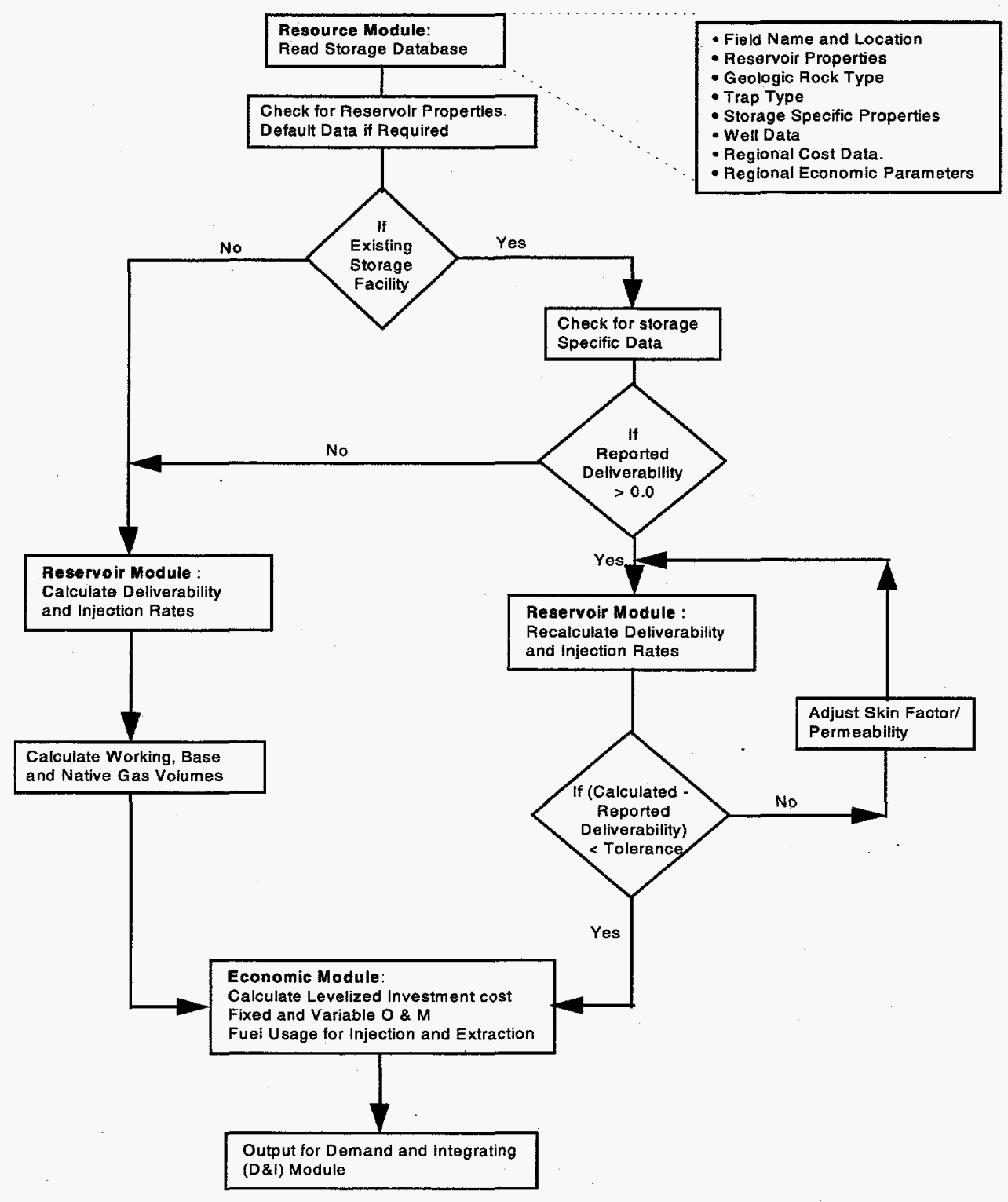

withdrawal rate of R4 MCF/Day which doesn't make the rate decline during the entire 100 day period. SRPM, does an internal check to ensure that total gas withdrawal during the 100 day period doesn't exceed the working gas.

In calculating the base gas and working gas for the reservoir, SRPM is run in full production (withdrawal) mode, at the design minimum flowing wellhead pressure. This provides the total technically recoverable gas production from the reservoir under a defined set of technology conditions. Working gas volume is assumed to be $90 \%$ of this technically recoverable number. Finally, the difference between original gas in place (OGIP) and this working gas volume provides the base and native cushion gas volumes for the reservoir. 


\section{FIGURE IV-2 \\ Illustration Of SRPM Process In Calculating Deliverability}

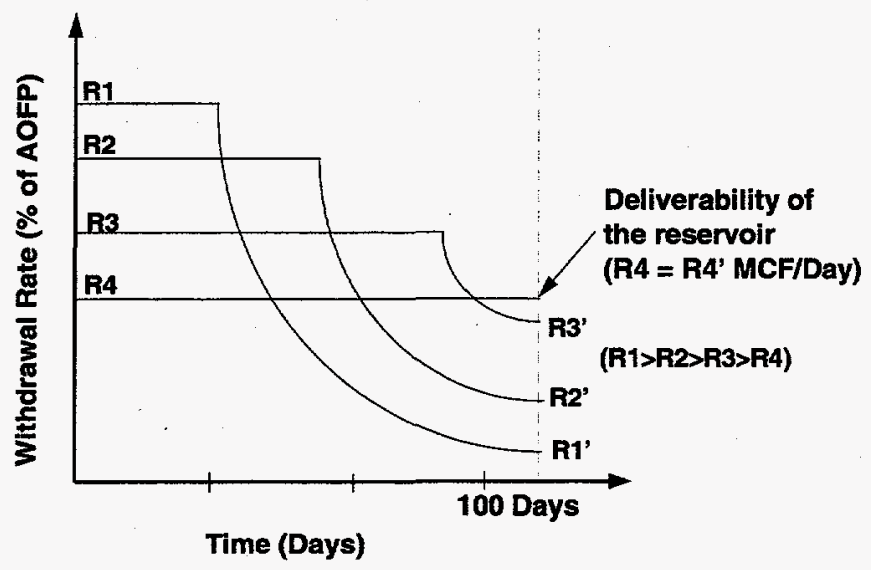

The type curve approach utilized in SRPM helps in designing the storage facility to meet specific deliverability needs. Figure IV-3 indicates a potential application of SRPM for such designs. This figure shows graphically how the wellhead pressure and the amount of working gas may be used to tailor a storage reservoir for a base load facility. This graph is for a reservoir that has a total OGIP of 22 BCF. Initial reservoir pressure is 1285 psia. Various minimum wellhead flowing pressures were assumed $(1000,800,600,400,250$ and $100 \mathrm{psia}$ ), and SRPM was run in full production (withdrawal) mode to create the working gas amount versus the deliverability, with flowing wellhead surface pressure as the changing parameter. Lines of constant time for emptying the reservoir at the rated deliverability are also drawn. For a base load storage facility design various choices are available. A base load unit with a working gas capacity of $2.7 \mathrm{BCF}$ could be developed with a flowing wellhead surface pressure of 1000 psia and a rated deliverability of $27 \mathrm{MMCF} / \mathrm{Day}$. This would require a certain amount of compressor horsepower and would require 100 days to empty at the rated deliverability.

A second choice of working gas of 5 BCF with a flowing wellhead pressure of 800 psia would give a rated deliverability of $50 \mathrm{MMCF} / \mathrm{Day}$ and would require less compressor horsepower. The time to employ would still be 100 days.

If the storage reservoir were to be developed as a base load facility for 175 days, a similar set of choices are available. Using 175 days to empty as a guide, some alternatives are available. The facility could be developed having $8.75 \mathrm{BCF}$ of working gas with a rated deliverability of $50 \mathrm{MMCF} / \mathrm{Day}$. The flowing wellhead pressure would be 600 psia. Another choice would be a facility with $6.3 \mathrm{BCF}$ of working gas, a rated deliverability of $36 \mathrm{MMCF} / \mathrm{Day}$, and a flowing wellhead pressure of $800 \mathrm{psia}$.

This particular analysis indicates that for a 100 day withdrawal cycle, the rated deliverability of the reservoir cannot exceed $50 \mathrm{MMCF} / \mathrm{Day}$ for a minimum flowing wellhead pressure design of 800 psia or less. In other words, the design minimum flowing wellhead pressure can be anywhere between 100 psia and 800 psia for a maximum deliverability of $50 \mathrm{MMCF} / \mathrm{Day}$ for 100 day withdrawal. A maximum working gas of $5 \mathrm{BCF}$ would be available from this reservoir in such cases.

The above example shows that considerable options are available in designing a storage facility by using various parameters to tailor a reservoir to a particular need. The choices are governed mostly by the economics and the particular storage needs. Figures IV-1 and IV-2 illustrate the SRPM reservoir deliverability calculation process and SRPM flowchart. 


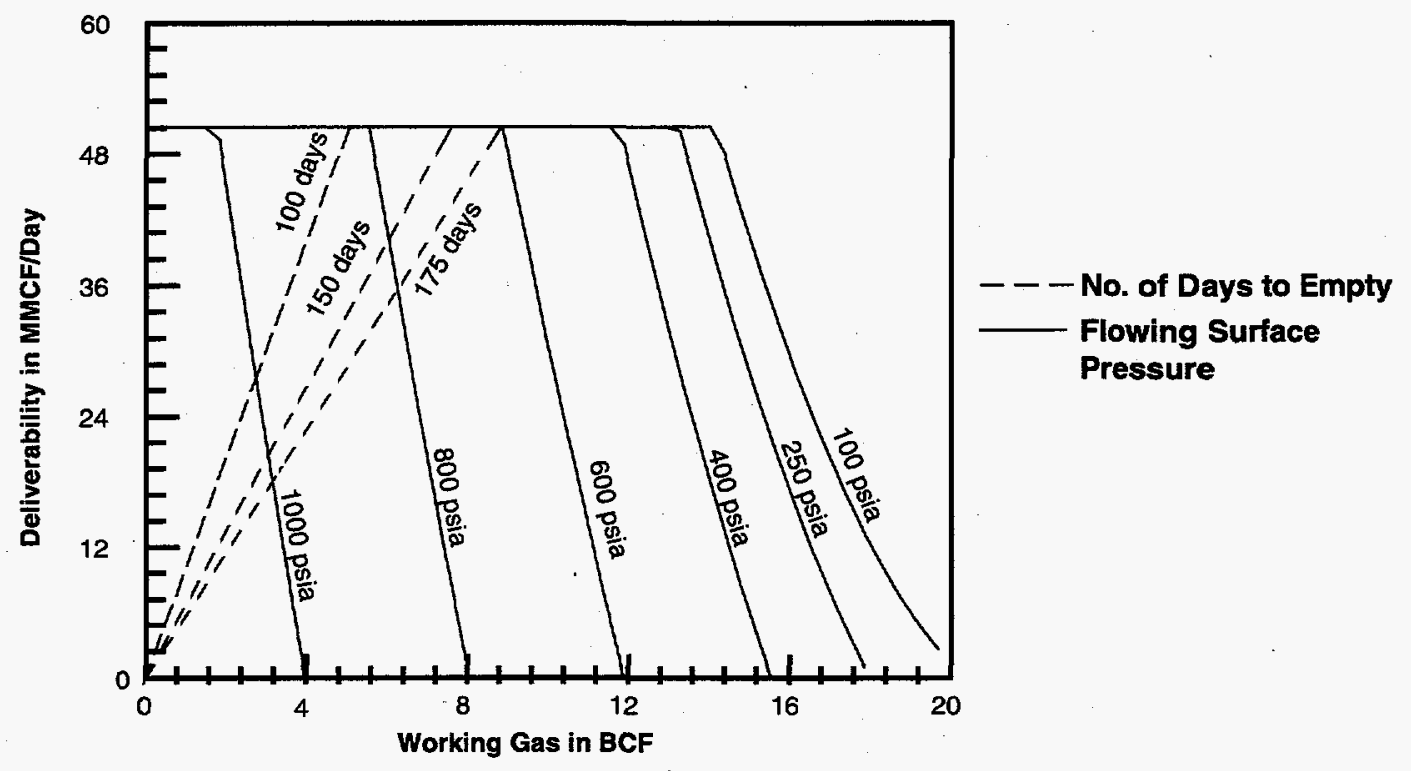

\section{- SRPM is Capable of Designing a Storage Facility Based on Particular Storage Needs and Economics.}

\section{Modification of the Demand and Integrating Module}

The Demand and Integrating Module (D\&I), in conjunction with other GSAM modules, balances the supply and demand sides of the natural gas market to determine market equilibrium prices and quantities. This is accomplished in part, by solving an integrating linear program (LP) which is based on maximizing total surplus (i.e., consumer surplus + producer surplus). This LP determines flows of gas along the pipeline network, various levels of storage, supply and demand, such that each region is balanced.

The modifications made to the D\&I for the storage project included incorporation of a data base for approximately 525 existing and new storage reservoirs directly into the integrating LP. Previously, only aggregate figures for each region were used. This storage data base is created in the new Storage Reservoir Performance Model (SRPM) and includes data on: capacity of the reservoir, maximum extraction and injection rates, the first year that the site is available, the fuel usage \%, as well as various relevant costs. A flowchart of the storage information is illustrated in Figure IV-4.

Because data on actual (or potential) storage reservoirs is used, the LP is able to select which reservoirs should be active as well as the appropriate levels for storage extraction and injection. Previously, only summary figures for the region as a whole could be obtained. Thus, specific storage reservoir-level information is made available in the output reports from the linear program.

\section{How Storage Variables Are Used in the Demand and Integrating Model}

One of the main functions of the integrating linear program is to determine optimal levels of storage (and other factors) so that supply and demand are balanced at each node (region) in the gas network. In particular the choice of when to use storage versus for example adding more pipeline capacity, is handled in the material balance constraints. 


\section{FIGURE IV-4 \\ Flow Chart of Storage Information}

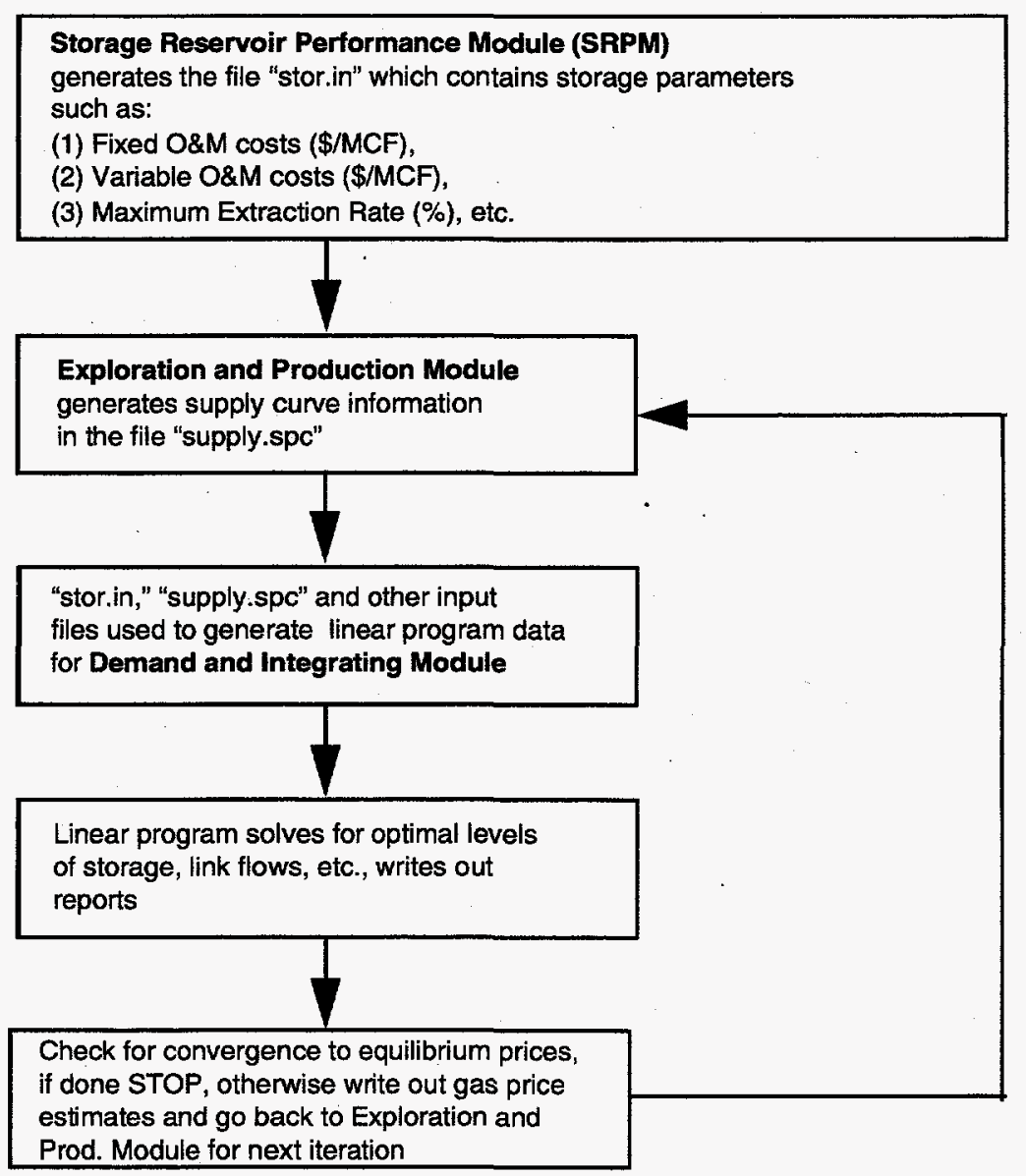

In these constraints, at a particular node, year, and season (winter or summer),

[the total net forward flow in + storage extraction] + [regular supply + peak supply + extra supply] $=$ [the total net reverse flow + storage injection + demand (residential, commercial, industrial, \& electric utility)]

Note that not every node has all of this supply and demand values so that the description above is the most general possible. The material balance constraints are depicted below in Figure IV-5.

Storage extraction and injection are selected over other options if the relative costs are less for storage than for these other alternatives. The costs (in \$/MCF) for storage activity are the levelized investment and the fixed O\&M, and the variable O\&M. The first two costs are relevant for activating/not activating the reservoir, the variable O\&M determines the actual level of storage activity that is desired. In addition to the material balance constraints, storage activity is constrained by extraction and injection capacities, the maximum capacity of the reservoir, and the loss of gas used for compression.

The main benefits of incorporating the new storage reservoir data base is that changes at the individual reservoir-level can now be analyzed whereas before, they could only be approximated at the regional level. This of course allows the user much more flexibility in analyzing storage cost/deliverability tradeoffs and the potential impacts of technology changes. 
FIGURE IV-5

Material Balance at Nodes

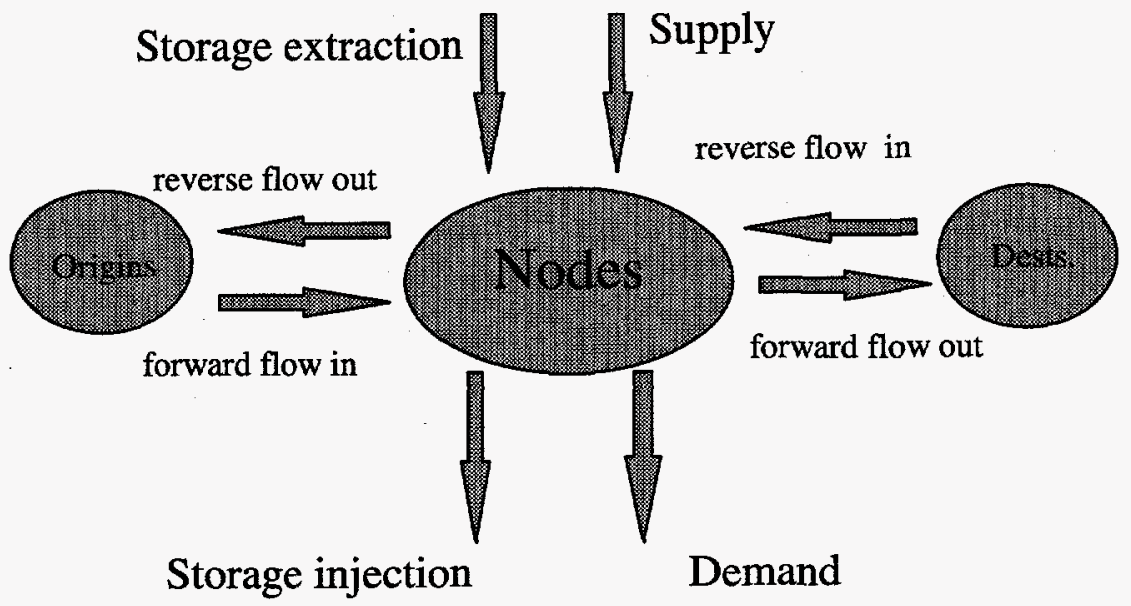




\section{Model Testing and Analysis of Storage Demand}

Upon completion of the gas storage module and its integration with the rest of GSAM, the module was used to test the demand for gas storage facilities under various scenarios. The scenarios were designed to assess how this demand might change under different economic and technological conditions. This chapter describes the results of these tests.

\section{A. Test Case Scenarios}

Four model run cases were tested to determine the effects on storage demand that result from changes in economic and technology scenarios. A Base Case, using essentially the status quo for supply, demand, and price parameters, provides the benchmark against which the other three cases are compared. Four of the Base Case assumptions are common to all four of the scenarios. They are: 1) gas continues to be exported from the U.S. to Mexico, 2) gas from Sable Island, Nova Scotia begins flowing into New England by 1995, 3) the Northern Border Pipeline capacity expansion of 700 million cubic feet per day is in service between 2000 and 2005, and 4) there are no major changes in environmental regulations through the forecast period to 2010 .

There are two scenarios that deal with economic changes from the Base Case. They are a Low Demand Case and a High Demand Case. The Low Demand Case differs from the Base Case only in the effects of gas and coal competition for fueling electric power generation. The Low Demand Case assumes that coal wins in competition with gas for this major growth market. Coal wins through lower coal prices relative to gas prices and by more rapid development of higher efficiency coal-fired generation technology. Since power generation is expected to be the major growth market for gas, any significant loss in market share to coal will reduce the future demand for gas.

The High Demand Case differs from the Base Case in that it assumes that gas wins in the competition with coal for power generation markets. Gas wins because it is assumed to be less expensive than coal and because gas-fired generation technology retains its efficiency lead over coal-fired technology.

The fourth scenario tested, the Technology Case, assumes that E\&P technology advances aggressively for both producing reservoirs and storage reservoirs, reducing the cost of finding, producing, and storing gas, primarily through improved well completion designs and practices. Changes from the Base Case include the use of both advanced well stimulation techniques and horizontal wells in reservoirs where these completions are appropriate. However, under this scenario, coal and gas remain highly competitive with each other to serve a growing electric power generation market.

Descriptions of these four scenarios are summarized in the following table. 
Scenario Summary

\begin{tabular}{|c|c|c|c|}
\hline Base Case & Low Demand Case & High Demand Case & Technology Case \\
\hline $\begin{array}{l}\text { Current electric market } \\
\text { for gas }\end{array}$ & $\begin{array}{l}\text { Coal wins electric } \\
\text { market }\end{array}$ & $\begin{array}{l}\text { Gas wins electric } \\
\text { market }\end{array}$ & $\begin{array}{l}\text { Current electric market } \\
\text { for gas }\end{array}$ \\
\hline $\begin{array}{l}\text { Evolutionary E\&P } \\
\text { technology }\end{array}$ & $\begin{array}{l}\text { Evolutionary E\&P } \\
\text { technology }\end{array}$ & $\begin{array}{l}\text { Evolutionary E\&P } \\
\text { technology }\end{array}$ & $\begin{array}{l}\text { Aggressive E\&P } \\
\text { technology for } \\
\text { producing \& storage } \\
\text { reservoirs }\end{array}$ \\
\hline $\begin{array}{l}\text { Current environmental } \\
\text { rules }\end{array}$ & $\begin{array}{l}\text { Current environmental } \\
\text { rules }\end{array}$ & $\begin{array}{l}\text { Current environmental } \\
\text { rules }\end{array}$ & $\begin{array}{l}\text { Current environmental } \\
\text { rules }\end{array}$ \\
\hline $\begin{array}{ll}\text { Expand } & \text { Northern } \\
\text { Border } & \end{array}$ & $\begin{array}{l}\text { Expand } \\
\text { Border }\end{array}$ & $\begin{array}{l}\text { Expand } \\
\text { Border }\end{array}$ & $\begin{array}{l}\text { Expand } \\
\text { Border }\end{array}$ \\
\hline $\begin{array}{ll}\text { Add Sable Island } \\
\text { pipeline }\end{array}$ & $\begin{array}{l}\text { Add Sable Island } \\
\text { pipeline }\end{array}$ & $\begin{array}{ll}\text { Add Sable Island } \\
\text { pipeline }\end{array}$ & $\begin{array}{l}\text { Add Sable Island } \\
\text { pipeline }\end{array}$ \\
\hline Export gas to Mexico & Export gas to Mexico & Export gas to Mexico & Export gas to Mexico \\
\hline
\end{tabular}

All of the cases assume that only 50 percent of the working gas capacity for each active gas storage reservoir is utilized in a year. This assumption was made for several reasons. First, it is unreasonable to assume that all working gas is withdrawn from each active storage reservoir every year, because of the difference in severity of winter weather. Although the future average annual capacity utilization of gas storage reservoirs is unknown, an initial assumption of 70 percent utilization resulted in essentially no new storage capacity being developed. Even at the 50 percent level for storage capacity utilization, many existing storage reservoirs are not chosen for operation by the storage module. The operation of the integrating linear program for finding optimal solutions to balancing supply and demand and the seasonal construction of GSAM both contribute to the low level of storage demand found in the four cases investigated. These modeling issues are described below.

The GSAM supply/demand integrating model optimizes the use of gas storage in balancing gas supplies and demand. It finds the least costly storage reservoir in a demand region and selects it for use, if its use results in lower gas costs than using additional gas pipeline capacity. The module uses all of the capacity available in that reservoir before looking for the next more expensive storage reservoir and comparing its costs to those of pipeline capacity. If allowed to use 100 percent of each storage reservoir's working capacity, far fewer existing storage reservoirs would be selected for operation each year. The storage optimization process looks at current economics for using either storage or more pipeline capacity and develops an efficient solution based on the fixed and variable costs of deliverability. Through this process the storage module has indicated that many existing storage reservoirs are uneconomic. This is reasonable to some extent, because there are probably numerous existing storage reservoirs that would not be developed today in competition with new storage or other supply alternatives.

The fact that GSAM is structured to recognize two seasons in a year is a major improvement over many energy models in widespread use today. Two seasons, for example, allows for gas storage injection and withdrawal periods, and provides a basis for comparing the economics of using gas pipeline capacity vs. storage capacity. However, a winter season of 151 days adds bias against storage demand. Because the model assumes an average winter demand over 151 days rather than a shorter peak demand period and that any new pipeline capacity will be used for 151 days, pipeline capacity can be justified unrealistically. Substantially more storage capacity would be justified if it were to be compared with the costs of providing pipeline capacity for a few peak demand days each winter. Until GSAM is modified to handle a shorter winter period, the benefits of gas storage will not be fully recognized. 
Despite these weaknesses in the GSAM analysis of demand levels for storage capacity, many valuable results have been developed through use of the storage module. The more efficient storage reservoirs in each region have been identified. Large differences in regional storage needs and excess storage capacities have been found. Major differences in the cost of using storage have been discovered. And lastly, the regional effects on storage demand from changing economic conditions and improvements in E\&P technologies have been computed. These results are discussed in the following section.

\section{B. Data Issues}

Several problems exist in the data available for both the existing storage reservoirs and the depleted reservoirs that are available for development as gas storage facilities. The most comprehensive data available for existing storage reservoirs is the American Gas Association (AGA) 1993 Report, Survey of Underground Gas Storage Facilities in the United States and Canada. This source does not provide any porosity or permeability values and many reporting companies have not provided data for all of the facility parameters listed. These missing data prevented precise physical characterizations of the reservoirs involved. These problems were overcome by estimating the missing properties based on the properties that are provided, from conversations with storage operators, the knowledge ICF Resources has regarding reservoirs in similar plays, and use of the U.S. Geological Survey play data.

The major problem for potential storage reservoirs is the lack of a data base for depleted reservoirs in the Appalachian region. Because this region is so highly dependent on gas storage, this omission had to be overcome. The solution was to generate representative data for a set of potential storage reservoirs using play characterizations based on data for existing storage reservoirs in the region and U.S. Geological Survey play data for the reservoirs that may be future candidates for storage facilities. A second problem with the depleted reservoir data was that some very large multi-reservoir fields are reported by NRG Associates, Inc. as single reservoirs, thereby overstating all of the capacity data. This problem was handled by deletion from the data base used in the study all of the "reservoirs" that were judged to be so large that re-pressuring costs would be prohibitive.

\section{Study Results}

Although the results of the four test scenarios are not considered to be precise regarding the demand for storage, for the reasons described above, they do support the conventional wisdom that storage capacity is in surplus in some parts of the U.S. The following paragraphs summarize the study findings for storage demand, storage costs, gas supply and demand, gas prices, and pipeline capacity additions. The demand regions used are illustrated in Figure V-1.

\section{Storage Demand}

The total regional gas storage demand (including both existing storage facilities and reservoirs selected for development of new storage facilities) selected by the GSAM demand and integrating module for the four scenarios analyzed are summarized in Table V-1. These storage demand volumes represent annual gas extractions from storage. 


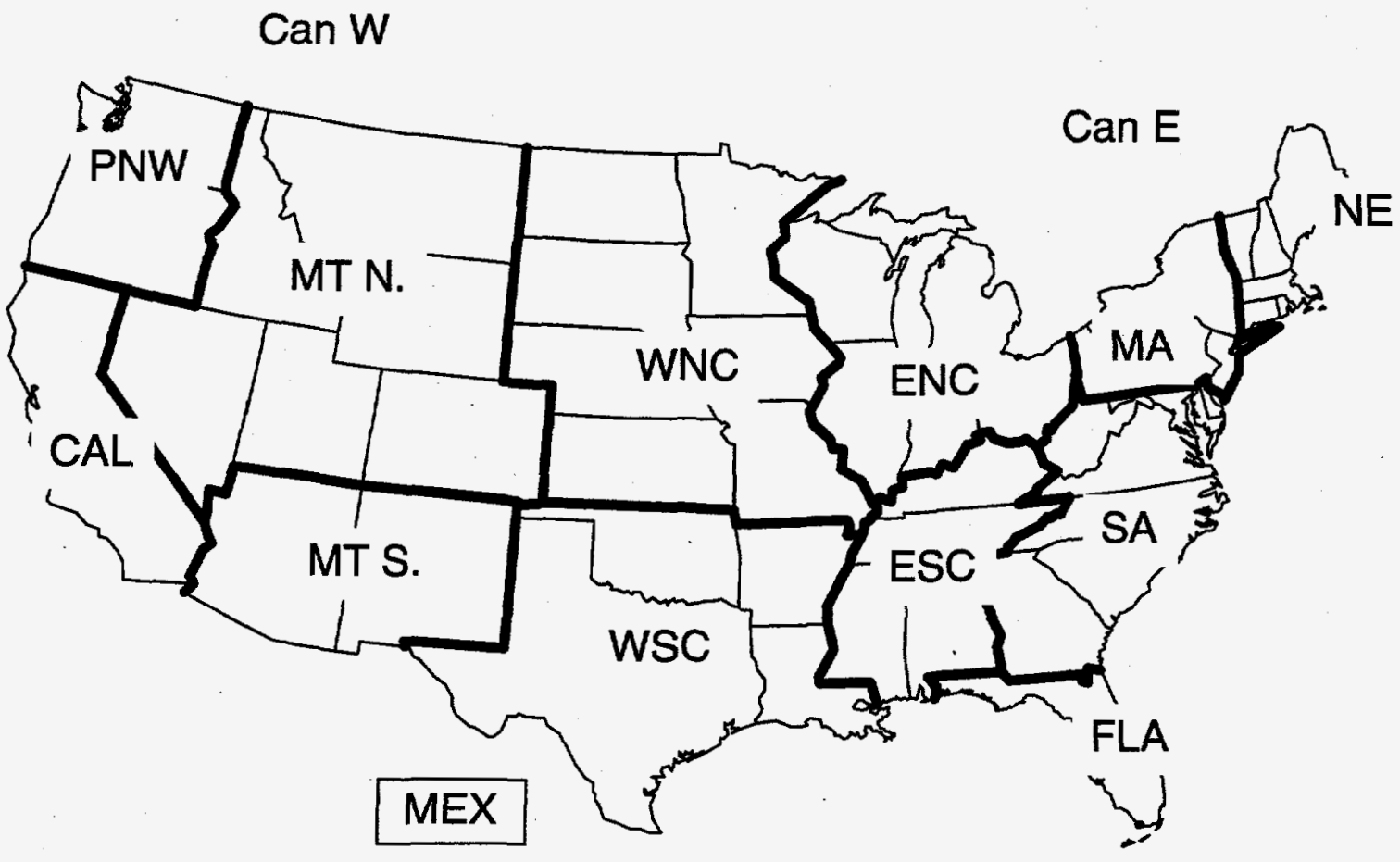

In all four scenarios, the demand for gas storage declines over the forecast period. There are two reasons for this decline. First, there is the model assumption that storage reservoir deliverability declines by five percent each year. For those reservoirs that have lower deliverabilities, this deliverability decline sometimes means that the working gas available for withdrawal cannot all be extracted in the 151-day winter period. Thus, depending on their maximum gas extraction rates, the volume that can be withdrawn from individual reservoirs tends to decline unevenly during the 1995 to 2010 forecast period. The demand for new storage facility development is inadequate to make up for these annual losses in withdrawal capacity. As explained earlier, the demand for new storage would likely be much larger if the GSAM winter season were structured to deal with peak demands rather than just a winter season demand.

The second reason for the declines in storage use is that most of the gas demand increases forecast are for electric power generation, rather than for temperature sensitive residential and commercial loads. With these seasonal loads making up a smaller part of total gas demand, the economic need for storage is reduced. The following table shows how the share of total gas demand used for electric generation grows in the four cases tested.

\section{Shares of Gas Demand Used for Power Generation}

\section{CASES}

Base

Low Demand

High Demand

Technology
2000

$20.0 \%$

$19.8 \%$

$20.2 \%$

$21.3 \%$
2005

$24.9 \%$

$20.4 \%$

$26.3 \%$

$26.9 \%$
2010

$26.6 \%$

$18.3 \%$

$29.6 \%$

$28.3 \%$ 
Although the 2010 U.S. demand for new storage in the Low Demand Case exceeds that for the Base Case, there is a rationale for this counter intuitive result. When comparing the Low Demand and Base Cases, most of the loss in gas demand that the Low Demand Case sees is for fueling less electric power generation. Because gas demand for power generation is highest in warmer months in most regions, this added summer load takes the place of some gas storage by helping keep pipelines full year round. On the other hand, in the Low Demand Case, coal fuels a larger share of power generation and the loss of this gas load causes gas demand to become more seasonal. Lower summer use of gas pipelines means that more gas storage can be economically justified.

\section{E. New Storage Facilities Added}

The number of new gas storage facilities selected by the demand and integration module for use between 2000 and 2010 varies from four for the Base Case to 11 for the Technology Case. All of the new storage facilities are forecast to start up in the year 2000 . The regions where these new facilities are forecast to be added are summarized in the following table.

\begin{tabular}{|c|c|c|c|c|c|c|}
\hline \multirow{3}{*}{ Region } & \multicolumn{5}{|c|}{ Extraction Rates for Storage Gas, Bcf } & \\
\hline & \multicolumn{3}{|c|}{ Base Case } & \multicolumn{3}{|c|}{ Low Demand Case } \\
\hline & 2,000 & 2005 & 2010 & 2,000 & 2005 & 2010 \\
\hline Mid Atlantic & 203 & 182 & 144 & 203 & 182 & 144 \\
\hline South Atlantic & 90 & 79 & 64 & 90 & 79 & 64 \\
\hline East South Central & 65 & 52 & 41 & 65 & 52 & 41 \\
\hline East North Central & 350 & 308 & 260 & 357 & 329 & 270 \\
\hline West South Central & 208 & 169 & 137 & 241 & 202 & 170 \\
\hline West North Central & 58 & 47 & 36 & 58 & 47 & 36 \\
\hline Mountain South & 2 & 1 & 1 & 16 & 15 & 15 \\
\hline Mountain North & 39 & 11 & 34 & 41 & 39 & 45 \\
\hline California & 62 & 56 & 48 & 73 & 68 & 58 \\
\hline \multirow[t]{2}{*}{ U.S. } & 1,077 & 905 & 765 & 1,144 & 1,013 & 843 \\
\hline & \multicolumn{3}{|c|}{ High Demand Case } & \multicolumn{3}{|c|}{ Technology Case } \\
\hline Region & 2,000 & 2005 & 2010 & 2,000 & 2005 & 2010 \\
\hline Mid Atlantic & 203 & 182 & 144 & 203 & 182 & 144 \\
\hline South Atlantic & 90 & 79 & 64 & 90 & 79 & 64 \\
\hline East South Central & 65 & 52 & 41 & 65 & 52 & 41 \\
\hline East North Central & 359 & 313 & 261 & 372 & 341 & 280 \\
\hline West South Central & 227 & 189 & 156 & 227 & 188 & 148 \\
\hline West North Central & 59 & 47 & 36 & 58 & 47 & 36 \\
\hline Mountain South & 2 & 1 & 1 & 57 & 56 & 51 \\
\hline Mountain North & 26 & 7 & 21 & 35 & 33 & 31 \\
\hline California & 67 & 61 & 52 & 78 & 72 & 59 \\
\hline U.S. & 1,098 & 931 & 776 & 1,185 & 1,050 & 854 \\
\hline
\end{tabular}




\section{Summary Of New Storage Facilities}

Region Base Case Low Demand Case High Demand Case $\begin{gathered}\text { Technology } \\ \text { Case }\end{gathered}$

East North Central

West South Central

Mountain South

California

Totals

$\begin{array}{ll}1 & 1 \\ 1 & 3 \\ 0 & 2 \\ 2 & 2 \\ 4 & \frac{2}{8}\end{array}$

1
3
0
$\frac{2}{6}$

2
2
5
2
11

The demand and integrating module selects new reservoirs in only four regions for the four scenarios tested. Thus, of the 12 U.S. demand regions in GSAM, eight require no new storage capacity under any of the scenarios analyzed. The only region that has new storage capacity added in all four cases analyzed is California. The Technology and Low Demand Cases require the most new storage facilities at 11 and 8 reservoirs, respectively. The demand for new storage capacity is lower in the High Demand Case than for the Low Demand Case for reasons described below.

Although the demand for new storage in the Low Demand Case exceeds that for the High Demand Case, there is a rationale for this counter intuitive result, similar to the reasons provided in the prior discussion of total storage capacity demand. When comparing the Low and High Demand Cases, all of the increase in gas demand that the High Demand Case sees is for fueling more electric power generation. Because gas demand for power generation is highest in warmer months in most regions, this added summer load takes the place of some gas storage by helping keep pipelines full year round. On the other hand, in the Low Demand Case, coal fuels a larger share of power generation and the loss of this gas load causes gas demand to become more seasonal. Lower summer use of gas pipelines means that more new gas storage can be economically justified.

The differences in U.S. gas demand for power generation fuel and total demand for gas are summarized in the following two tables.

\section{Summary Of U.S. Gas Demand for Power Generation, Bcf}

$\begin{array}{ccccc}\text { Year } & \text { Base Case } & \begin{array}{c}\text { Low Demand } \\ \text { Case }\end{array} & \begin{array}{c}\text { High Demand } \\ \text { Case }\end{array} & \text { Technology Case } \\ 1995 & 3,322 & 3,268 & & \\ 2000 & 4,450 & 4,471 & 3,354 & 3,424 \\ 2005 & 5,924 & 4,859 & 4,554 & 4,899 \\ 2010 & 6,330 & 4,360 & 6,387 & 6,936 \\ & & & 7,259 & 6,995\end{array}$

Summary of Total U.S. Gas Demand, Bcf

$\begin{array}{ccccc}\text { Year } & \text { Base Case } & \begin{array}{c}\text { Low Demand } \\ \text { Case }\end{array} & \begin{array}{c}\text { High Demand } \\ \text { Case }\end{array} & \text { Technology Case } \\ 1995 & 20,108 & 20,028 & 20,152 & \\ 2000 & 22,188 & 22,294 & 22,465 & 20,304 \\ 2005 & 24,216 & 23,327 & 24,511 & 22,951 \\ 2010 & 24,815 & 23,016 & 25,326 & 25,890 \\ & & & & 25,600\end{array}$


These tables show that in the year 2010, for example, gas demand to fuel power plants is 3,862 Bcf higher in the High Demand Case than in the Low Demand Case. In this same year total gas demand is only 3,265 Bcf higher in the High Demand Case, indicating that the other consuming sectors (residential, commercial, and industrial) had reduced demands for gas in this case. Higher gas prices in the High Demand Case are largely the cause for this loss of demand in these three sectors. Gas price projections are discussed in a later section.

\section{F. Use of Existing Gas Storage Facilities}

Across the four cases studied, the projected utilization of existing working gas capacity in the ten regions that have underground storage facilities varies from zero to 100 percent. As an example, neither of the two storage facilities in the Pacific Northwest region are selected for use. In the Base, High Demand and Technology Cases, gas demand growth in the Pacific Northwest is projected to be handled by additional pipeline capacity from the Rockies Foreland supply area. In the Low Demand Case, neither storage or new pipeline capacity are required for the Pacific Northwest. At the other extreme, the only storage reservoir in the Mountain South states of New Mexico and Arizona is always used. Similarly, in the Middle Atlantic and South Atlantic regions, storage capacity utilization varies from 97 to 100 percent in the four cases studied. In the other six regions storage capacity utilization ranges from 12 to 91 percent. The following table summarizes these storage utilization percentages for the ten storage regions.

\section{Summary of Capacity Utilization Rates for Existing Gas Storage}

$\begin{array}{lcccc}\text { Region } & \text { Base Case } & \begin{array}{c}\text { Low Demand } \\ \text { Case }\end{array} & \begin{array}{c}\text { High Demand } \\ \text { Case }\end{array} & \begin{array}{c}\text { Technology Case } \\ \text { Mid Atlantic }\end{array} \\ \text { South Atlantic } & 100 \% & 100 \% & 100 \% & 100 \% \\ \text { East So. Central } & 97 \% & 97 \% & 97 \% & 97 \% \\ \text { East No. Central } & 91 \% & 91 \% & 91 \% & 91 \% \\ \text { West So. Central } & 60 \% & 63 \% & 61 \% & 63 \% \\ \text { West No. Central } & 83 \% & 94 \% & 83 \% & 83 \% \\ \text { Mountain South } & 49 \% & 49 \% & 49 \% & 49 \% \\ \text { Mountain North } & 100 \% & 100 \% & 100 \% & 100 \% \\ \text { Pacific NW } & 74 \% & 74 \% & 74 \% & 74 \% \\ \text { California } & 0 \% & 0 \% & 0 \% & 0 \\ \text { U.S. } & 90 \% & 90 \% & 90 \% & 90 \% \\ \end{array}$

Although we cannot be sure that these capacity utilization values show the true economic use of existing gas storage facilities, they do indicate the variation in storage needs among the regions. These values tend to support the general belief that storage is over built in the East North Central, West North Central, and Mountain North regions. The fact that the East North Central region is shown to need only about 60 percent of its storage capacity and yet adds one or two new facilities in each case occurs because many of the existing reservoirs have low deliverability rates per unit of their cost of service. Because of this poor economic efficiency many of the East North Central region storage facilities are not chosen for use in any of the cases studied. The new storage reservoirs chosen for the East North Central have substantially higher gas deliverability rates per unit of cost than the existing facilities that are not selected.

In addition to the 8 new storage facilities developed in the Low Demand Case, as described earlier, the projected need for more storage capacity caused an additional ten existing storage reservoirs to be used that were not used in the Base Case. A different trend occurs in the High Demand and 
Technology Cases, the storage module selects several additional existing gas storage reservoirs for use and shuts down some existing storage facilities in the East North Central region that were used in the Base Case. This change in selection of which existing storage reservoirs to use in the High Demand and Technology Cases is caused by the more costly deliverability of many East North Central storage facilities. The following table shows the regions in which these changes in the use of existing storage facilities occur.

\section{Summary Of Changes In Existing Storage Facility Use Compared To The Base Case}

\section{Region}

Middle Atlantic

East South Central

East North Central

West South Central

Mountain North

\author{
Low Demand Case \\ 1 Facility Added \\ No change \\ 5 Facilities Added \\ 3 Facilities Added \\ 1 Facility Added
}

\author{
High Demand Case \\ No change \\ No change \\ 1 Facility Added \& \\ 3 Facilities Dropped \\ No change \\ No change
}

\author{
Technology Case \\ No change \\ No change \\ 1 Facility Added \& \\ 1 Facility Dropped \\ 1 Facility Added \\ 1 Facility Added
}

\section{G. Gas Pipeline Capacity Additions}

In the process of optimizing gas supply to meet growing demand, the demand and integrating module found that the efficient approach to increased gas deliveries was a mixture of adding gas storage capacity and more gas pipeline capacity. The following table shows where pipeline expansions occur, when the expansions began, and how much pipeline capacity was demanded by the year 2010 , for the four cases analyzed. By far the larger expansions were needed from the Gulf of Mexico West to the Texas Gulf Coast and from the Mid-Continent to the Mountain North region, for all four scenarios. Also there was a major expansion on TransCanada Pipelines from Alberta to Canada East for the High Demand Case.

\section{Gas Pipeline Capacity Additions, MMcfd}

\begin{tabular}{|c|c|c|c|c|c|c|c|c|c|c|c|c|}
\hline \multirow[b]{2}{*}{ Location } & \multicolumn{3}{|c|}{ Base Case Capacities } & \multicolumn{3}{|c|}{ Low Demand Case Capacities } & \multicolumn{3}{|c|}{ High Demand Case Capacities } & \multicolumn{3}{|c|}{ Technology Case Capacities } \\
\hline & Initial & Expan.Yr. & Final & Initial & Expan.Yr. & Final & Initial & Expan.Yr. & Final & Initial & Expan.Yr. & Final \\
\hline Alberta to Canada East & 4,053 & 2005 & 6,982 & 4,053 & 2010 & 4,223 & 4,053 & 2000 & 7,204 & 4,053 & 2000 & 5,596 \\
\hline South La. to Florida & 1,957 & None & 1,957 & 1,957 & None & 1,957 & 1,957 & None & 1,957 & 1,957 & 2000 & 2,492 \\
\hline Gulf of Mex.W to Tex.Gulf Cst & 2,662 & 2000 & 6,606 & 2,662 & 2000 & 7,011 & 2,662 & 2000 & 6,903 & $2, \overline{662}$ & 2000 & 6,899 \\
\hline Mountain N. to Mid Cont. & 385 & 2005 & 8,580 & 385 & 2005 & 7,458 & 385 & 2005 & 8,832 & 385 & 2005 & 9,437 \\
\hline Mountain N. to San Juan & 150 & 2000 & 2,235 & 150 & 2000 & 1,802 & 150 & 2000 & 2,387 & 150 & 1995 & 4,551 \\
\hline Rockies to Pacific Northwest & 254 & 2005 & 415 & 254 & None & 254 & 254 & 2005 & 810 & 254 & 2005 & 456 \\
\hline San Juan to Permian & 987 & None & 987 & 987 & 2010 & 1,305 & 987 & None & 987 & 987 & 2010 & 4,071 \\
\hline Alberra to West N Central & 1,568 & 2005 & 2,268 & 1,568 & 2000 & 2,268 & 1,568 & 2000 & 2,268 & 1,568 & 2000 & 2,268 \\
\hline Rockies to West N Gentral & 547 & 2000 & 1,147 & 547 & 2000 & 1,147 & 547 & 2000 & 7,147 & 547 & 2005 & 1,147 \\
\hline
\end{tabular}

\section{H. Storage Prices}

Tariff rates for gas storage service are typically comprised of two monthly fixed charges, one for storage capacity and the other for withdrawal deliverability. Variable volumetric rates are charged for the amounts of gas injected and withdrawn and sometimes a separate fuel charge based on storage use. Typical variable rates would be one or two cents per Mcf injected and another one or two cents for volumes withdrawn. The fixed charges are many times the size of the variable costs, bringing the tariff rates of storage up to a range of from $\$ 0.30$ to $\$ 1.40$ per Mcf, depending on the age of the facility. Older 
facilities are typically much less expensive than newer ones. A major cause of this difference is the cost of the capitalized base gas in the reservoir. Today's base gas value can be ten times that of 25 years ago.

The ranges of storage rates for the facilities used in each region are summarized in the following table. Rates for the facilities not chosen by the storage module were in some cases substantially higher than the rates shown here.

Price Ranges For Gas Storage Facilities Used, \$/Mcf

Region

Middle Atlantic

South Atlantic

Florida

East South Central

East North Central

West South Centra

West North Central

Mountain South

Mountain North

California

Pacific Northwest

\section{Base Case}

$\$ 0.17$ to $\$ 0.92$

$\$ 0.26$ to $\$ 0.62$

None used

$\$ 0.16$ to $\$ 1.13$

$\$ 0.15$ to $\$ 1.63$

$\$ 0.11$ to $\$ 0.90$

$\$ 0.30$ to $\$ 0.97$

$\$ 0.22$

$\$ 0.17$ to $\$ 0.78$

$\$ 0.29$ to $\$ 1.04$

None used

Low Demand
$\$ 0.17$ to $\$ 0.92$
$\$ 0.25$ to $\$ 0.62$
None used
$\$ 0.16$ to $\$ 1.13$
$\$ 0.15$ to $\$ 1.63$
$\$ 0.11$ to $\$ 1.10$
$\$ 0.30$ to $\$ 0.97$
$\$ 0.22$
$\$ 0.17$ to $\$ 0.78$
$\$ 0.29$ to $\$ 1.03$
None used

\section{Low Demand Case}

$\begin{array}{ll}\text { High Demand Case } & \text { Technology Case } \\ & \\ \$ 0.17 \text { to } \$ 0.93 & \$ 0.16 \text { to } \$ 0.92 \\ \$ 0.26 \text { to } \$ 0.63 & \$ 0.28 \text { to } \$ 0.62 \\ \text { None used } & \text { None used } \\ \$ 0.16 \text { to } \$ 1.13 & \$ 0.16 \text { to } \$ 1.13 \\ \$ 0.21 \text { to } \$ 1.38 & \$ 0.15 \text { to } \$ 1.38 \\ \$ 0.11 \text { to } \$ 0.91 & \$ 0.11 \text { to } \$ 0.90 \\ \$ 0.30 \text { to } \$ 0.97 & \$ 0.30 \text { to } \$ 0.97 \\ \$ 0.22 & \$ 0.22 \\ \$ 0.17 \text { to } \$ 0.78 & \$ 0.17 \text { to } \$ 0.78 \\ \$ 0.29 \text { to } \$ 1.04 & \$ 0.29 \text { to } \$ 1.04 \\ \text { None used } & \text { None used }\end{array}$

These gas storage prices were developed in two ways. Prices for existing gas storage facilities were based on cost of service tariff rates filed by the owners or operators. Prices for new storage facilities were calculated, based on reservoir properties, the investments required to develop them, and estimated operating and maintenance costs. The procedure for calculating storage costs for the individual reservoirs in existing storage facilities and new facilities is described in Chapter IV.

\section{Gas Supply}

The GSAM net U.S. gas supply forecasts that support the storage demand results of this study vary from a low of 19,278 Bcf in the Low Demand Case for the year 1995 to a high of 25,708 Bcf for the year 2010 in the High Demand Case. These supply figures include U.S. gas production and peak shaving volumes, but exclude imports. The following table summarizes total supplies for each of the four scenarios.

\section{Summary of Total U.S. Gas Supply, Bcf}

$\begin{array}{rrrcc}\text { Year } & \text { Base Case } & \text { Low Demand Case } & \text { High Demand Case } & \text { Technology Case } \\ 1995 & 19,309 & 19,278 & 19,397 & 19,637 \\ 2000 & 21,976 & 22,060 & 22,253 & 22,559 \\ 2005 & 24,054 & 23,202 & 24,300 & 26,232 \\ 2010 & 24,222 & 22,547 & 24,728 & 25,708\end{array}$

Between 1995 and 2010 gas imports from Canada continue to grow as they have in recent years. By 2010 Canadian gas supply to the U.S. in the Base Case grows by another 15 percent, reaching 3,245 Bcf. In the Low Demand Case the 2010 total is 2,948 Bcf, an increase from 1995 of less than five percent. Even less Canadian gas is needed to meet U.S. demand by 2010 in the Technology Case, as U.S. supply costs are lowered and domestic supply increases. In the Technology Case, the growth in Canadian gas imports from 1995 is only a little over one percent, reaching 2,827 Bcf in 2010. A summary of Canadian gas imports for the four scenarios is provided in the following table. 
Summary Of Canadian Gas Imports, Bcf

Year

1995

2000

2005

2015
Base Case

2,829
2,522
2,804
3,245

Low Demand Case

2,816

2,593

2,551

2,948
High Demand Case

2,817

2,600

2,772

3,296
Technology Case

2,790

2,768

2,598

2,827

\section{J. Gas Prices}

Improving E\&P technology and an accessible resource base provide the foregoing supply volumes at relatively small price increases until the year 2010, when average U.S. prices for the preceding five years climb by 32 to 72 percent, among the four scenarios tested. The lowest average U.S. price projections are for the Technology Case, reaching only $\$ 2.00$ per Mcf by the year 2010 . The highest 2010 price is found in the High Demand Case at $\$ 2.35$ per Mcf. The following table summarizes gas supply prices for the total U.S. and several supply areas for the four scenarios analyzed

TABLE V-2

\section{Summary Of Gas Supply Prices, 1995\$/Mcf}

\begin{tabular}{cccccc} 
Location & Year & Base Case & $\begin{array}{c}\text { Low Demand } \\
\text { Case }\end{array}$ & $\begin{array}{c}\text { High Demand } \\
\text { Case }\end{array}$ & $\begin{array}{c}\text { Technology } \\
\text { Case }\end{array}$ \\
U.S. Average & 1995 & 1.23 & 1.20 & 1.38 & 1.32 \\
& 2000 & 1.38 & 1.40 & 1.27 & 1.21 \\
& 2005 & 1.64 & 1.34 & 1.74 & 1.16 \\
Rockies & 2010 & 2.17 & 2.03 & 2.35 & 2.00 \\
& 1995 & 1.04 & 1.07 & 0.99 & 0.95 \\
& 2000 & 1.01 & 0.98 & 0.88 & 0.87 \\
Alberta & 2005 & 1.19 & 0.92 & 1.27 & 0.74 \\
& 2010 & 1.69 & 1.56 & 1.85 & 1.52 \\
& 1995 & 0.90 & 0.91 & & \\
& 2000 & 1.18 & 1.21 & 1.05 & 0.89 \\
\multirow{3}{*}{ Gulf of Mex. West } & 2005 & 1.25 & 1.22 & 1.36 & 0.67 \\
& 2010 & 1.69 & 1.63 & 1.87 & 1.97 \\
& 1995 & 0.94 & & & \\
& 2000 & 1.25 & 1.28 & 1.37 & 1.30 \\
& 2005 & 1.49 & 1.18 & 1.15 & 1.06 \\
Appalachia & 2010 & 2.32 & 2.16 & 1.68 & 1.11 \\
& 1995 & 1.63 & 1.65 & & 2.39 \\
& 2000 & 1.67 & 1.70 & 1.62 & 1.55 \\
& 2005 & 2.02 & 1.71 & 2.12 & 1.46 \\
& 2010 & 2.63 & 2.45 & 2.85 & 2.52 \\
& & & & &
\end{tabular}

By the year 2010, the highest gas prices among all of the regions shown occur in the High Demand Case and the lowest prices are in the Technology and Low Demand Cases. Consistent with history, the highest price seen in 2010 is in the Appalachian region at \$2.85 per Mcf in the High Demand Case. The lowest price in the year 2010 among all regions occurs in the Williston Basin at \$1.48 per Mcf in the Technology Case. 
Examples of consumer prices in several demand regions that these gas supply prices translate to after adding delivery charges are summarized in Table V-3. The range of consumer prices is illustrated by the electric power generation and residential sectors. The five demand regions shown are the largest in the U.S.

\section{TABLE V-3}

\section{Examples of Regional Gas Prices for Electric and Residential Sectors, 1995\$/Mcf}

\begin{tabular}{|c|c|c|c|c|c|c|}
\hline Region & Sector & Year & $\begin{array}{l}\text { Base } \\
\text { Case }\end{array}$ & $\begin{array}{c}\text { Low Demand } \\
\text { Case }\end{array}$ & $\begin{array}{l}\text { High Demand } \\
\text { Case }\end{array}$ & $\begin{array}{c}\text { Technology } \\
\text { Case }\end{array}$ \\
\hline Mid Atlantic & $\begin{array}{l}\text { Electric } \\
\text { Residential }\end{array}$ & $\begin{array}{l}1995 \\
2010 \\
1995 \\
2010\end{array}$ & $\begin{array}{l}1.58 \\
2.44 \\
6.96 \\
8.10\end{array}$ & $\begin{array}{l}1.62 \\
2.19 \\
6.97 \\
7.96\end{array}$ & $\begin{array}{l}1.57 \\
2.96 \\
6.94 \\
8.25\end{array}$ & $\begin{array}{l}1.55 \\
2.54 \\
6.83 \\
7.92\end{array}$ \\
\hline S. Atlantic & $\begin{array}{l}\text { Electric } \\
\text { Residential }\end{array}$ & $\begin{array}{l}1995 \\
2010 \\
1995 \\
2010\end{array}$ & $\begin{array}{l}1.56 \\
2.74 \\
6.47 \\
7.68\end{array}$ & $\begin{array}{l}1.59 \\
2.42 \\
6.48 \\
7.54\end{array}$ & $\begin{array}{l}1.55 \\
2.66 \\
6.45 \\
7.82\end{array}$ & $\begin{array}{l}1.55 \\
2.73 \\
6.34 \\
7.48\end{array}$ \\
\hline E.N.Central & $\begin{array}{l}\text { Electric } \\
\text { Residential }\end{array}$ & $\begin{array}{l}1995 \\
2010 \\
1995 \\
2010\end{array}$ & $\begin{array}{l}1.50 \\
2.31 \\
4.99 \\
6.07\end{array}$ & $\begin{array}{l}1.54 \\
2.08 \\
5.00 \\
5.98\end{array}$ & $\begin{array}{l}1.48 \\
2.86 \\
4.98 \\
6.23\end{array}$ & $\begin{array}{l}1.47 \\
2.31 \\
4.87 \\
5.89\end{array}$ \\
\hline W.S.Central & $\begin{array}{l}\text { Electric } \\
\text { Residential }\end{array}$ & $\begin{array}{l}1995 \\
2010 \\
1995 \\
2010\end{array}$ & $\begin{array}{l}1.36 \\
2.21 \\
5.14 \\
6.17\end{array}$ & $\begin{array}{l}1.40 \\
1.93 \\
5.15 \\
6.07\end{array}$ & $\begin{array}{l}1.35 \\
2.54 \\
5.12 \\
6.34\end{array}$ & $\begin{array}{l}1.33 \\
2.18 \\
5.02 \\
6.00\end{array}$ \\
\hline California & $\begin{array}{l}\text { Electric } \\
\text { Residential }\end{array}$ & $\begin{array}{l}1995 \\
2010 \\
1995 \\
2010\end{array}$ & $\begin{array}{l}1.70 \\
2.33 \\
5.98 \\
6.60\end{array}$ & $\begin{array}{l}1.73 \\
2.00 \\
5.99 \\
6.41\end{array}$ & $\begin{array}{l}1.63 \\
2.65 \\
5.92 \\
6.82\end{array}$ & $\begin{array}{l}1.61 \\
2.24 \\
5.85 \\
6.47\end{array}$ \\
\hline
\end{tabular}

As should be expected, gas prices for power generation are lowest in the West South Central region where gas is plentiful and alternative fuel prices are relatively low. By contrast, residential gas prices for the regions shown here are highest in the Middle Atlantic states where gas transmission distances are greater and alternate fuel prices are relatively high. The higher gas prices for electric generation appear in the South Atlantic region. Residential prices are lowest in the East North Central region for all scenarios. 